\title{
The H3.3K27M oncohistone antagonizes reprogramming in Drosophila
}

\author{
Kami Ahmad ${ }^{1 *}$ and Steven Henikoff ${ }^{1,2}$ \\ ${ }^{1}$ Basic Sciences Division, Fred Hutchinson Cancer Research Center, 1100 N. Fairview Ave, Seattle, WA, 98109 \\ ${ }^{2}$ Howard Hughes Medical Institute, USA
}

*Corresponding author: kahmad@fredhutch.org

\begin{abstract}
Development proceeds by the activation of genes by transcription factors and the inactivation of others by chromatin-mediated gene silencing. In some cases development can be reversed or redirected by mis-expression of master regulator transcription factors. This must involve the activation of previously silenced genes, and such developmental aberrations are thought to underlie a variety of cancers. Here, we express the wing-specific Vestigial master regulator to reprogram the developing eye, and test the role of silencing in reprogramming using an H3.3K27M oncohistone mutation that dominantly inhibits histone $\mathrm{H} 3 \mathrm{~K} 27$ trimethylation. We find that expression of the oncohistone blocks eye-to-wing reprogramming. CUT\&Tag chromatin profiling of mutant tissues shows that H3K27me3 domains are globally reduced with oncohistone expression, suggesting that previous developmental programs must be silenced for effective transformation. Strikingly, mis-expressed Vg and H3.3K27M synergize to stimulate overgrowth of eye tissue, a phenotype that resembles that of mutations in Polycomb Repressive Complex 1 components. Our results imply that growth dysregulation can result from the simple combination of crippled silencing and transcription factor mis-expression, an effect that may explain the origins of oncohistone-bearing cancers.
\end{abstract}

\section{Introduction}

Developmental programs in multicellular organisms are specified by transcription factors that activate and repress batteries of genes, thereby determining cell fate. Ectopic expression of specific transcription factors drive changes in cell fate, either by inducing pluripotency from a differentiated state [Takahashi \& Yamanaka, 2006], or by transforming one cell type to another in a process referred to as 'transdetermination' or 'direct reprogramming' [Graf, 2011]. Aberrant reprogramming induced by transcription factor misexpression underlies some developmental and malignant diseases.

In eukaryotes transcription factors interact with chromatin, where genomic DNA is wrapped around histone octamers in nucleosomes. Silencing histone modifications on nucleosomes inhibit factor binding and transcription, and so modulate gene expression programs. Silencing has been suggested to impose directional- ity and reliability to developmental progression [Perino \& Veenstra, 2016]. A key chromatin mechanism is mediated by trimethylation of the lysine-27 residue of histone H3 (H3K27me3) which is bound by Polycomb proteins. Mutations of Polycomb proteins derepress developmental transcription factor genes and thereby induce aberrant fate transformations in animals, plants, and fungi, highlighting the conserved importance of this chromatin system [Lanzuolo \& Orlando, 2012; Bemer \& Grossniklaus, 2012; Lewis, 2017].

In Drosophila, mutation of the histone H3-K27 residue recapitulates Polycomb transformations [Pengelly et al, 2013]. In humans, screening of cancer cells identified mutations of this residue in certain pediatric glioblastomas [Schwartzentruber et al, 2012; Wu et al, 2012]. These oncohistone mutations are lysine-to-methionine (K27M) mis-sense substitutions that dominantly inhibit the EZH1/2 histone methyltransferases and reduce chromatin methylation [Chan et al, 2013; Lewis et al, 2013; Bender et al, 2013; Justin et al, 2016; Stafford et al, 2018]. The oncohistone is not tumorigenic on its own, but may precondition cells to later oncogenic mutations [Pathania et al, 2017; Mohammad \& Helin, 2017]. However, since the critical window for tumorigenesis is in early developing lineages, the sequence of initiating events is not accessible to analysis.

Histones and histone modifying enzymes are conserved across eukaryotes, and expression of the H3K27M oncohistone in Drosophila cells recapitulates chromatin and silencing defects seen in gliomas [Herz et al, 2014]. Here, we use Drosophila to show that the H3K27M oncohistone blocks direct reprogramming induced by ectopic expression of the wing master regulator transcriptional activator Vestigial $(\mathrm{Vg})$. While oncohistone expression on its own inhibits cell proliferation, co-expression with $\mathrm{Vg}$ results in overgrowth of cells, and these cells retain eye identity. Chromatin profiling by CUT\&Tag [Kaya-Okur et al, 2019] shows widespread reduction in H3K27me3 histone modification that may cripple silencing during reprogramming. These effects demonstrate that a defect in chromatin 
silencing combined with aberrant transcription factor expression is sufficient to induce neoplastic growth, with implications for the developmental origins of gliomas.

\section{Results}

The H3K27M oncohistone blocks direct reprogramming

To probe the interaction between reprogramming and chromatin silencing, we used inducible transgenes for the $\mathrm{Vg}$ master regulator transcription factor and for the H3.3K27M oncohistone. Vg encodes transcriptional activation domains and - when heterodimerized with the DNA-binding Scalloped (Sd) protein - determines the identity of cells in the pouch of wing imaginal discs [Ruiz-Losada et al, 2018]. $\mathrm{Vg}$ is a master regulator of wing development, as ectopic expression of $\mathrm{Vg}$ converts tissue into wing structures [Kim et al, 1996]. We used the eyeless-GAL4 (eyGAL) driver to induce transgene expression during development of the eye [Hazelett et al, 1998]. Expression of $\mathrm{Vg}$ in the eye is semi-lethal (Table 1), and many dying pupae have small heads that lack eye tissue (Figure 1A,B). Those adults that survive show varying degrees of transformation: some animals lack eyes, while other have reduced numbers of eye ommatidia and have darkly pigmented outgrowths resembling wing tissue with small bristles and trichome-like hairs instead of the setae of normal eyes (Figure 1C; Table 1), indicating reprogramming of the eye by the $\mathrm{Vg}$ master regulator.

We dissected and immunostained developing eye-antennal imaginal discs to determine the cellular effects of ectopic $\mathrm{Vg}$ and $\mathrm{H} 3.3 \mathrm{~K} 27 \mathrm{M}$. The eyGAL driver induces expression of an RFP reporter gene, marking the eye anlagen of the imaginal disc (Figure 1D). Inducing $\mathrm{Vg}$ expression reduces and distorts the eye portion of discs, with very few photoreceptors developing at the posterior edge of the eye disc (Figure 1E). RFP reporter expression is also reduced in these discs, consistent with the inactivation of the eyGAL driver as $\mathrm{Vg}$ reprograms the eye disc.

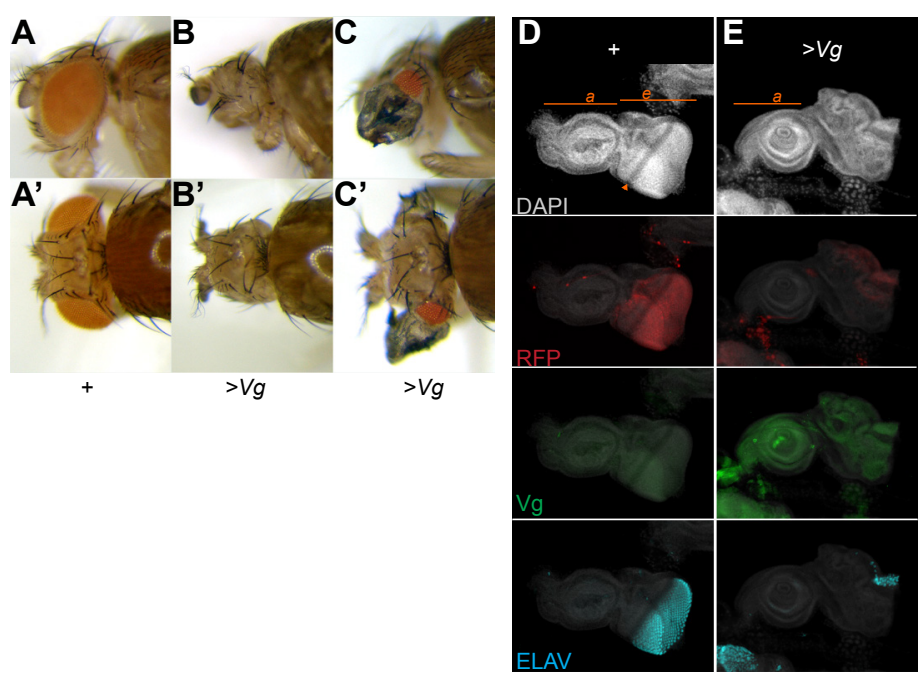

Figure 1. Vg expression transforms the eye into wing tissue. (A-C) Side and dorsal views of the head and eyes of wildtype adults (A) and ey $G A L>V g$ adults (B,C). Most adults with $>V g$ expression display pigmented wing-like projections, while some lack eyes entirely. (D,E) Eye-antennal imaginal discs from wildtype larvae (D) and from larvae with $>V g$ expression (E). The eyGAL driver also induces a $U A S-R F P$ reporter, and discs were immunostained for the $\mathrm{Vg}$ protein and for ELAV, a marker of differentiating photoreceptors. The antennal (a) and eye (e) portions of the disc are indicated, and the morphogenetic furrow that separates mitotically active undifferentiated cells in the anterior of the eye from differentiating photoreceptors in the posterior is marked with an orange arrowhead. The eye portions of discs with Vg expression are distorted with low RFP expression, Vg expression, and very few differentiating photoreceptors at the posterior edge.

Table 1. Effect of induced $\mathrm{Vg}$ and H3.3 mutations on eye-to-wing reprogramming.

eyGAL

\begin{tabular}{|c|c|c|c|c|c|c|c|}
\hline & & & $>H 3.3 K 27 M$ & $>H 3.3$ & $>H 3.3 K 27 M$ & $>H 3.3 K 27 R$ & $>H 3.3 \mathrm{~K} 9 \mathrm{M}$ \\
\hline & + & $>V g$ & & $>V g$ & $>V g$ & $>V g$ & $>V g$ \\
\hline viability $^{\mathrm{a}}$ & 1 & 0.5 & 0.8 & 0.4 & 0.8 & 0.4 & 0.3 \\
\hline normal eyes & 1 & 0 & 0 & 0 & 0 & 0 & 0 \\
\hline reduced eyes & 0 & 0 & 1 & 0.1 & 0.02 & 0.1 & 0.05 \\
\hline no eyes & 0 & 0.1 & 0 & 0.3 & 0.02 & 0.1 & 0.25 \\
\hline winged eyes & 0 & 0.9 & 0 & 0.6 & 0 & 0.8 & 0.7 \\
\hline convoluted eyes & 0 & 0 & 0 & 0 & 0.96 & 0 & 0 \\
\hline
\end{tabular}

afraction of eclosing pupae. Viable progeny were scored for eye phenotypes. 

available under aCC-BY-NC-ND 4.0 International license.

We used a transgene encoding an inducible $H 3.3 K 27 M$ gene [Ahmad \& Spens 2019] and the same eyGAL driver to express the oncohistone in the eye. Oncohistone expression decreases the size of the adult eye in proportion to the amount of oncohistone produced (Figure $2 \mathrm{~A}-\mathrm{C})$. Thus, while the oncohistone is associated with proliferation in cancers, expression on its own inhibits tissue growth. Expression of the oncohistone results in reduced staining for $\mathrm{H} 3 \mathrm{~K} 27 \mathrm{me} 3$ specifically in the eye portion of the disc with normal levels of staining in the antennal portion (Figure 2D,F,G). These discs are slightly smaller than wildtype discs, but with normal morphology and development of photoreceptors (Figure $2 \mathrm{D}, \mathrm{G}$ ). In contrast, the $\mathrm{H} 3 \mathrm{~K} 27 \mathrm{me} 3$ modification is unaffected by ectopic expression of $\mathrm{Vg}$, with high levels in cells of both the eye and antennal portions of discs (Figure 2H).
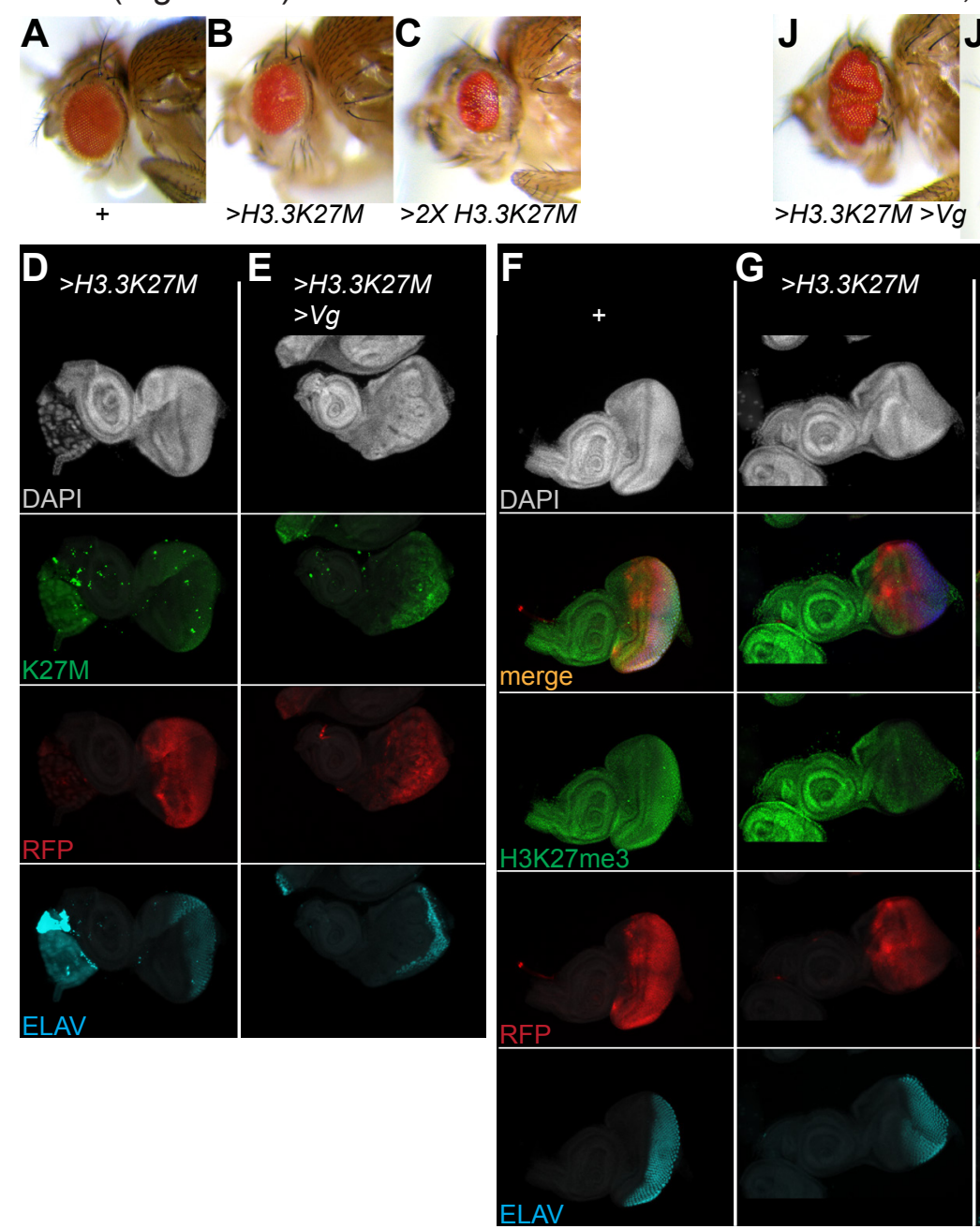

To test the importance of $\mathrm{H} 3 \mathrm{~K} 27 \mathrm{me} 3$ chromatin silencing in reprogramming, we co-induced expression of $\mathrm{Vg}$ and the $\mathrm{K} 27 \mathrm{M}$ oncohistone together in developing eyes. Surprisingly, co-expression completely suppressed eye-to-wing reprogramming (Table 1). The majority of animals co-expressing $\mathrm{Vg}$ and $\mathrm{H} 3.3 \mathrm{~K} 27 \mathrm{M}$ eclose, but have grossly disrupted eyes with a variety of projections, stalks, and folds (Figure 2J,K). These convoluted eyes contain ommatidia with no wing-like tissue, suggesting that co-expression of the oncohistone completely blocks the reprogramming effects of $\mathrm{Vg}$, thereby maintaining the eye identity of these cells. This is apparent in developing imaginal discs, where the eye portion of discs is greatly expanded where the oncohistone is expressed, with developing photoreceptors along a convoluted edge of the disc (Figure $2 \mathrm{E}, \mathrm{I})$. Suppression of reprogramming is specific to the

Figure 2. H3.3K27M oncohistones block direct reprogramming. (A-C) Side views of eyes of wildtype adults (A), adults with one $H 3.3 K 27 M$ transgene (B), or with two H3.3K27M transgenes (C). Expression of the oncohistone reduces the size of the eye. (D,E) Eye-antennal imaginal discs from larvae with eyGAL-induced expression of $R F P, H 3.3 \mathrm{~K} 27 \mathrm{M}$, and $V g$. Discs were immunostained for the K27M epitope and for the photoreceptor ELAV marker. The oncohistone is expressed throughout the developing eye portion of the disc. (F-I) Eye-antennal imaginal discs with eyGAL-induced expression of $R F P, H 3.3 K 27 M$, and $V g$, and immunostained for the H3K27me3 histone modification and for ELAV. Histone methylation is reduced in the eye portion of the disc relative to staining in the antennal portion in discs expressing the oncohistone. $(J, K)$ Examples of adults with co-expression of $\mathrm{Vg}$ and $\mathrm{H} 3.3 \mathrm{~K} 27 \mathrm{M}$ in the eye. Eyes are overgrown and convoluted $(\mathrm{J})$ or overgrown with extreme projections $(\mathrm{K})$. 
$\mathrm{K} 27 \mathrm{M}$ oncohistone, because a transgene with a wildtype H3.3 histone, with an H3.3K27R substitution, or with an H3K9M substitution [Herz et al, 2014] do not block reprogramming (Table 1 ). We tested additional independent eyGAL4 driver constructs and insertions to induce the H3.3K27M oncohistone and to induce $\mathrm{Vg}$ (see Key Resources Table), all of which reproduced the phenotypes of $\mathrm{Vg}$-induced reprogramming and oncohistone-induced overgrowth. Thus, transcription factor-induced reprogramming of the eye specifically requires H3K27me3-mediated silencing.

\section{$\mathrm{Vg}$ and H3K27M induce cell death and proliferation}

The sizes of imaginal discs and adult eyes are consistent with decreased proliferation with either $\mathrm{Vg}$ or with H3.3K27M expression, but increased proliferation with the two proteins co-expressed. We examined cell division rates and cell death rates by staining eye imaginal discs with a mitotic marker histone (H3S10-phosphorylation) and with a cell death marker (cleaved DCP-1). In wildtype controls, mitoses are scattered throughout the anterior portion of the eye disc, but mostly absent in the posterior region once photoreceptors start to differentiate (Figure $3 \mathrm{~A}$ ) with negligible cell death (Figure $3 \mathrm{E})$. Expression of H3.3K27M does not affect mitosis in the disc (Figure 3B), but a stripe of cell death appears across the disc where cells transition from proliferating to differentiating regions (Figure 3F). This implies that the reduction in eye size with $\mathrm{H} 3.3 \mathrm{~K} 27 \mathrm{M}$ expression is at least in part due to reduced cell viability. In contrast, induction of $\mathrm{Vg}$ is associated with increased mitosis and increased cell death throughout the disc (Figure $3 C, G)$. Thus, reduced cell viability limits the size of the reprogrammed tissue. Finally, co-expression of $\mathrm{H} 3.3 \mathrm{~K} 27 \mathrm{M}$ and $\mathrm{Vg}$ produces very large discs with patches of mitosis frequently apparent (Figure 3D), but these discs show extensive cell death in undifferentiated regions (Figure $3 \mathrm{H}$ ). The hyperproliferation of some regions accounts for overgrowth in spite of extensive oncohistone-induced cell death in other regions.

\section{Gene expression in Vg-reprogrammed tissues}

Reprogramming of the eye inactivates the eyGAL driver once cells transform, and this is apparent by reduced RFP expression when $\mathrm{Vg}$ is induced (Figure 1E). Inactivation of the eyGAL driver implies that the $\mathrm{Vg}$ transgene will also be inactivated, and so the endogenous vg gene must be activated for successful reprogramming. To test this, we constructed animals with the ey$G A L$ driver and the inducible $\mathrm{Vg}$ transgene, but lacking the endogenous $v g$ gene. As expected, these animals have very small eyes with no wing tissue outgrowths (Figure 4A). This implies that transient expression of $\mathrm{Vg}$ activates endogenous genes for wing specification.
The endogenous $v g$ gene is also required for overgrowth of eye discs with oncohistone and ectopic $\mathrm{Vg}$ expression, as a dominant negative $\mathrm{vg}^{U}$ allele reduces eye size (Figure 4B).
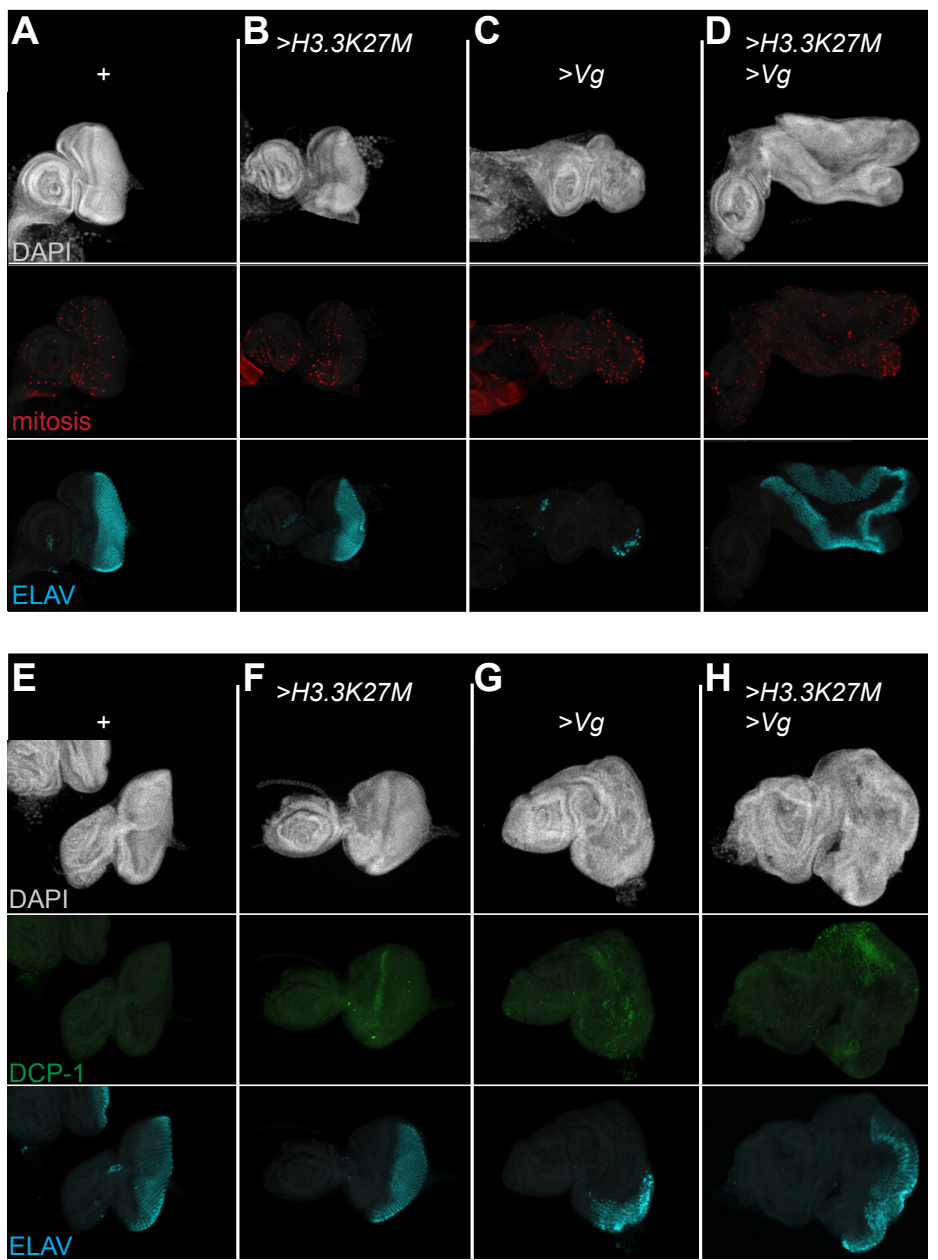

Figure 3. H3.3K27M and Vg stimulate cell death and proliferation. Eye-antennal discs with eyGAL-induced expression of H3.3K27M and Vg and immunostained for the H3S10-phosphorylation marker of mitosis (A-D) and for the cleaved DCP-1 marker of apoptosis $(\mathbf{E}-\mathbf{H})$. All discs were immunostained for ELAV.

To characterize activation of wing-specific genes further, we stained discs for proteins specific for eyes or for wings. Expression of the wing specification factors Nubbin (Nub) in reprogrammed eye discs is weaker than in wing discs (Figure 4G-I), implying that the wing determination program is not efficiently activated. These discs continue to express the eye factor Dacshund (Dac), although the normal striped pattern of this factor is distorted by the gross disorganization of the reprogrammed disc (Figure $4 \mathrm{C}-\mathrm{F}$ ). Notably, there is no expression of Nub in $>H 3.3 K 27 M>V g$ overgrown discs (Figure 4J), while RFP and Dac are highly expressed. Thus, in this setting the ectopic expression of $\mathrm{Vg}$ does not activate wing determination and eye factors continue to be expressed (Figure 4F). 
bioRxiv preprint doi: https://doi.org/10.1101/2020.11.10.375881; this version posted November 11,2020 . The copyright holder for this preprint

(which was not certified by peer review) is the author/funder, who has granted bioRxiv a license to display the preprint in perpetuity. It is made available under aCC-BY-NC-ND 4.0 International license.
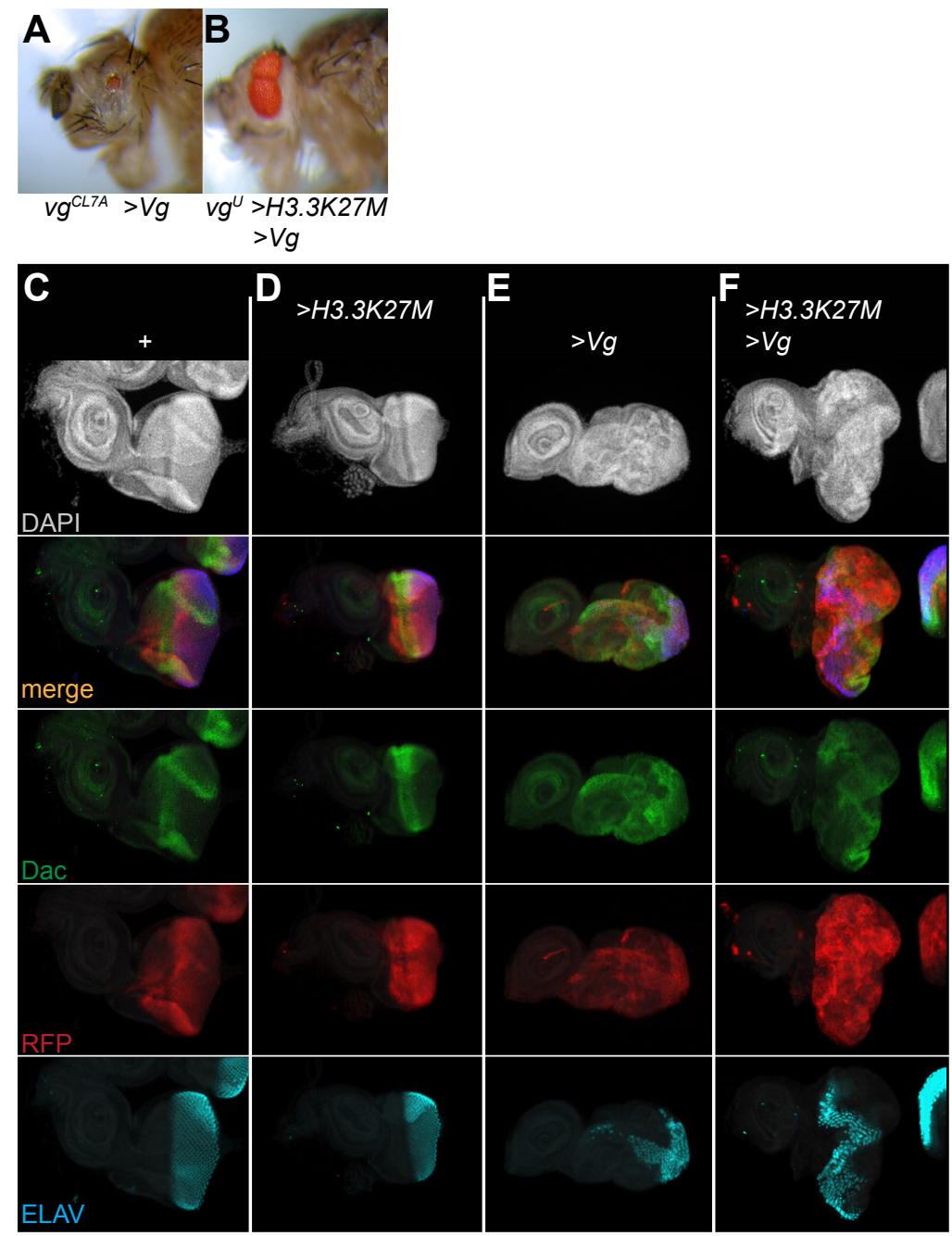

Figure 4. Tissue-specific gene expression changes during direct reprogramming. (A) Side view of a $\mathrm{vg}^{C L 7 A}$ mutant adult with eyGAL-induced Vg expression in the eye. Eye size is reduced, but not transformed. (B) Side view of a $\mathrm{vg}^{U /+}$ head with eyGAL-induced H3.3K27M and Vg co-expression in the eye. The eye is convoluted, but reduced in size instead of overgrown. (C-F) Eye-antennal discs with eyGAL-induced expression of RFP, H3.3K27M and Vg and immunostained for the eye-specific Dac and ELAV proteins. Neither Vg nor H3.3K27M expression prevent Dac expression, although these discs are disorganized. (G-K) Wildtype wing imaginal discs $(\mathbf{G})$ and eye-antennal discs with eyGAL-induced expression of $\mathrm{H} 3.3 \mathrm{~K} 27 \mathrm{M}$ and $\mathrm{Vg}(\mathbf{H}-\mathbf{K})$ immunostained for the wing-specific Nub protein and ELAV. The wing pouch is heavily labeled with Nub, and eye discs with Vg expression have patches with low level Nub staining.

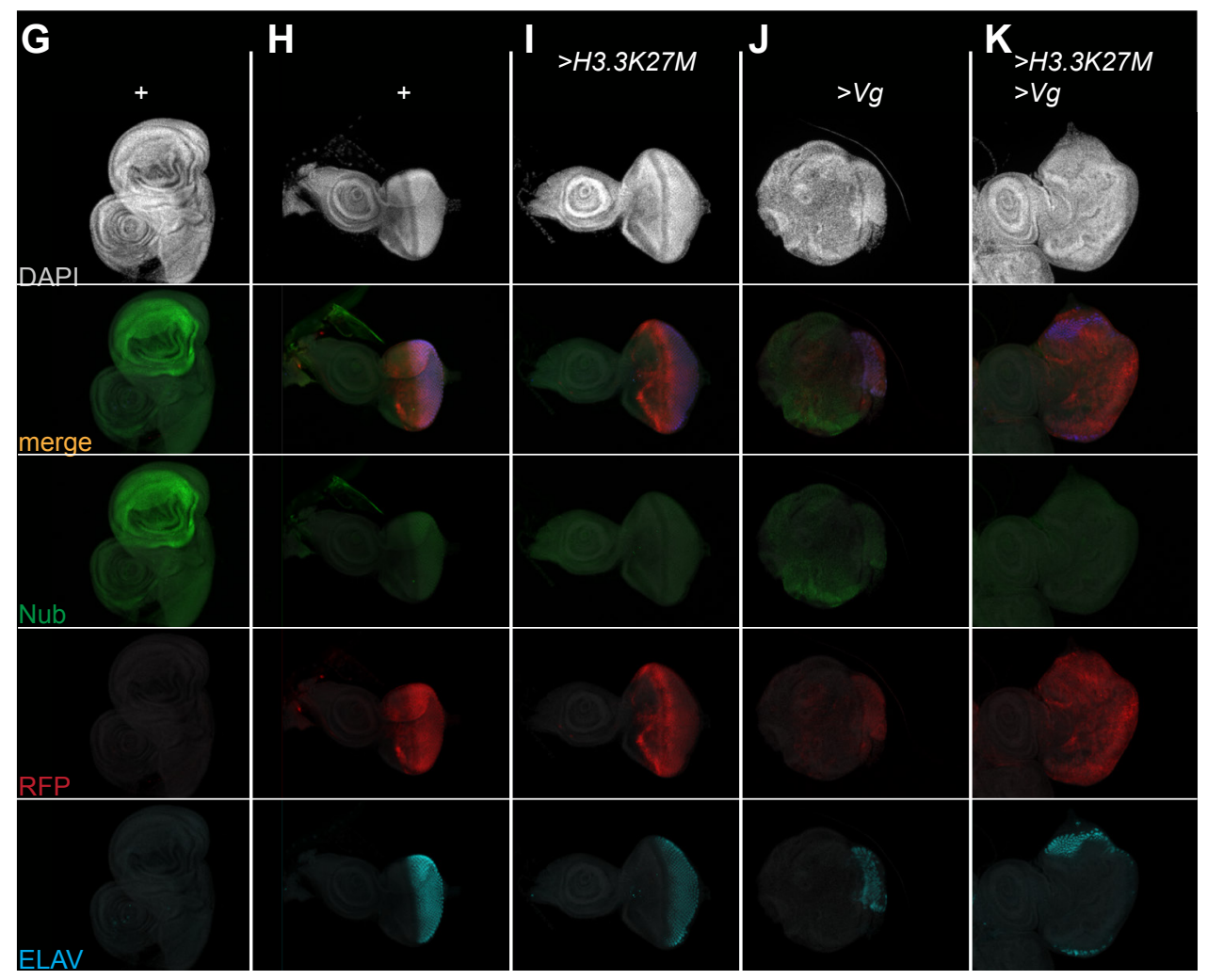




\section{Chromatin profiling of H3K27me3 domains in re- programmed tissues}

To profile chromatin domains in Vg-reprogrammed eyes, we adapted the CUT\&Tag method [Kaya-Okur et al, 2019] for dissected imaginal discs from Drosophila larvae. CUT\&Tag works by first soaking unfixed cells with a factor-specific antibody which binds to chromatin sites, followed by decoration with a secondary antibody. Next, a protein-A-Tn5 (pA-Tn5) transpososome loaded with sequencing adapters is soaked in, binding to the chromatin-bound antibodies. Activation of the tethered transpososome by adding magnesium then integrates sequencing adapters around binding sites, and sequencing of the resulting library thus maps the targeted chromatin protein. We have previously adapted the micrococcal nuclease-based CUT\&RUN method for dissected imaginal discs [Ahmad \& Spens, 2019], and adjusting buffers for CUT\&Tag works reliably. For CUT\&Tag with tissue samples, we dissect wing or eye imaginal discs, coat them with Concanavalin A magnetic beads for handling, lightly permeabilize them with digitonin, and sequentially incubate with antibodies and then with pA-Tn5. Resulting libraries are subjected to Illumina paired-end sequencing and mapped to the Drosophila dm6 genome assembly. Imaginal discs from 2-3 larvae were sufficient to generate chromatin profiles, although the capacity of CUT\&Tag to profile very small sample sizes should work with even less tissue [Kaya-Okur et al, 2019; Kaya-Okur et al, 2020].

We first mapped the H3K27me3 silencing modification in eye and wing imaginal discs from wildtype larvae (Supplementary Information; Supplementary Figure 1A-C). Previous studies found that H3K27me3-marked domains are shared between larval tissues but with quantitative differences in chromatin methylation that correspond to expression of included genes [Loubière et al, 2016; Ahmad \& Spens, 2019]. For example, a $350 \mathrm{~kb}$ H3K27me3 domain encompasses the ANTENNAPEDIA-COMPLEX (ANTP-C) cluster of homeobox genes in both eye and wing imaginal disc cells (Figure 5A). In eye imaginal discs the Antp gene is silenced and heavily coated with H3K27me3-marked chromatin, while in wing imaginal discs the Antp gene is transcribed, and H3K27me 3 across this gene is correspondingly depleted. Similarly, H3K27me3 domains with regulatory genes differentially-expressed between wings and eyes show quantitative changes in histone methylation: chromatin encompassing the wing-specific apterous (ap) gene is methylated in both eye and wing imaginal discs, but noticeably reduced in wing tissue, while the eye-specific sine oculus (so) and optix genes have less methylation in eye tissue (Figure 5B). Thus, activation of tissue-specific genes in H3K27me3 domains is accompanied by the reduction of histone methylation, but complete removal of this mark is not required for expression.

To quantify changes in chromatin landscapes, we measured the average H3K27me3 signal across 166 annotated H3K27me3 domains and 16 control regions (Supplementary Information) in wing and eye discs and compared these on a scatter plot (Figure 5C). Domains that encompass genes involved in eye specification have lower chromatin methylation in eye discs and gain signal in wing discs when the genes are inactive. The opposite trend occurs for four wing specification genes. Comparing the rank order of average domain methylation, eye specification genes substantially lose methylation (Figure 5D). In contrast, wing specification genes gain methylation in eye tissue, even though 3 of these 4 genes have substantial H3K27me3 signal in both tissues (Figure 5D).

We dissected away the antennal portion of the disc to profile H3K27me3 in reprogrammed eye tissue without contamination from wildtype antennal cells. Unlike the differences between eye and wing discs, expression of $\mathrm{Vg}$ in eye discs results in little change in H3K27me3 across domains compared to their chromatin signal in eye discs (Figure 5C,D; Supplementary Figure 1D). Thus, reprogramming of eye cells is not accompanied by dramatic changes in chromatin methylation patterns.

We next looked at the effect of the H3.3K27M oncohistone on $\mathrm{H} 3 \mathrm{~K} 27$ me 3 patterns in the eye. The oncohistone is incorporated into chromatin by histone H3.3-specific chaperones at active promoters and enhancers, and at lower levels by DNA replication throughout the genome [Chan et al, 2013; Piunti et al, 2017; Mohammad et al, 2017; Sarthy et al, 2020], and expression of H3.3K27M in eye discs gives a similar promoter enrichment with background throughout the genome when profiled using an antibody to the K27M epitope (Supplementary Figure 1E). Expression of the oncohistone reduces H3K27me3 staining (Figure 2G,I), and quantitative chromatin profiling of glioma cell lines has previously shown that H3K27me 3 is globally reduced but a few domains remain [Sarthy et al, 2020]. By profiling eye portions of imaginal discs with oncohistone expression, we find that H3K27me3 still coats domains, although with more dispersion between domains that we attribute to the lower H3K27me3 signal in oncohistone-expressing cells (Figure 5C). In Drosophila H3K27me3 domains are nucleated at nucleosome-depleted Polycomb Response Elements (PREs), and chromatin methylation then spreads out across the domain [Laprell et al 2017]. The H3.3K27M oncohistone specifically inter- 
bioRxiv preprint doi: https://doi.org/10.1101/2020.11.10.375881; this version posted November 11,2020 . The copyright holder for this preprint (which was not certified by peer review) is the author/funder, who has granted bioRxiv a license to display the preprint in perpetuity. It is made available under aCC-BY-NC-ND 4.0 International license.

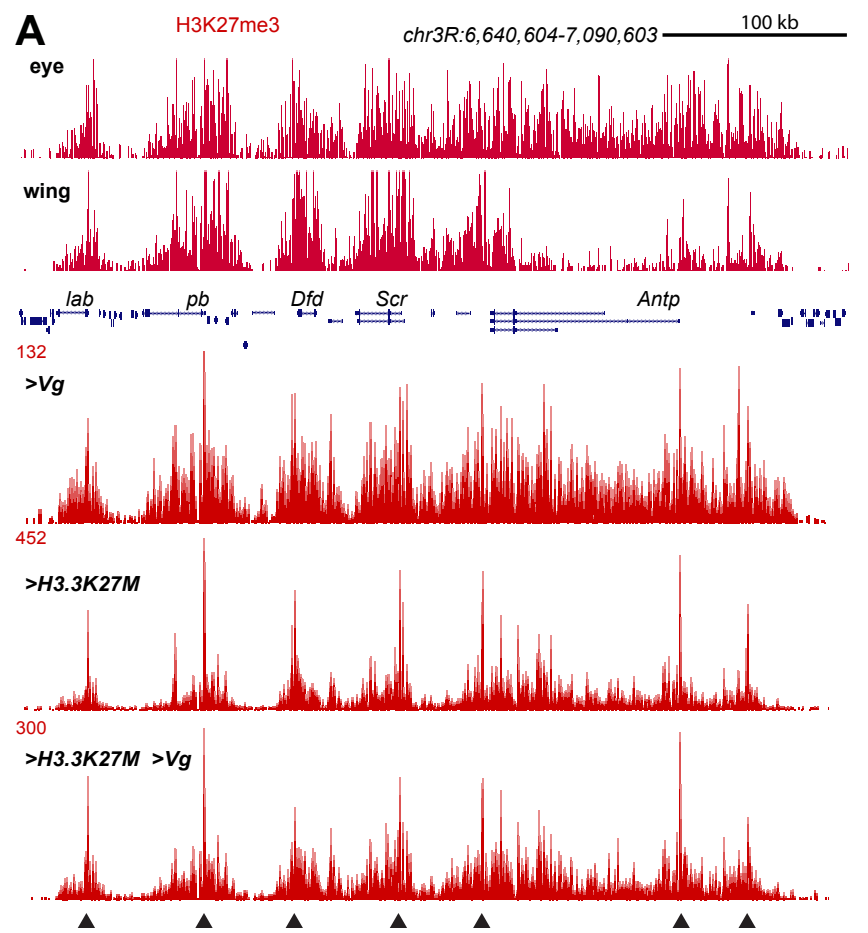

B H3K27me3 chr2R:5,656,001-8, 156,000

D H3K27me3 domains E H3K27me3 around PREs

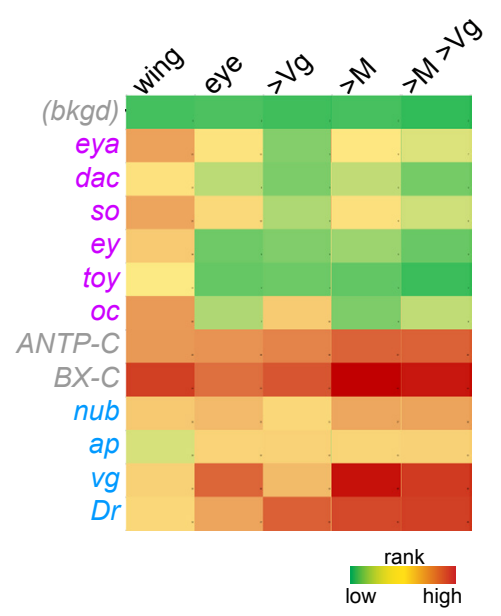

C mean $\mathrm{H} 3 \mathrm{~K} 27 \mathrm{me} 3$ in domains

domains bkgd eye wing
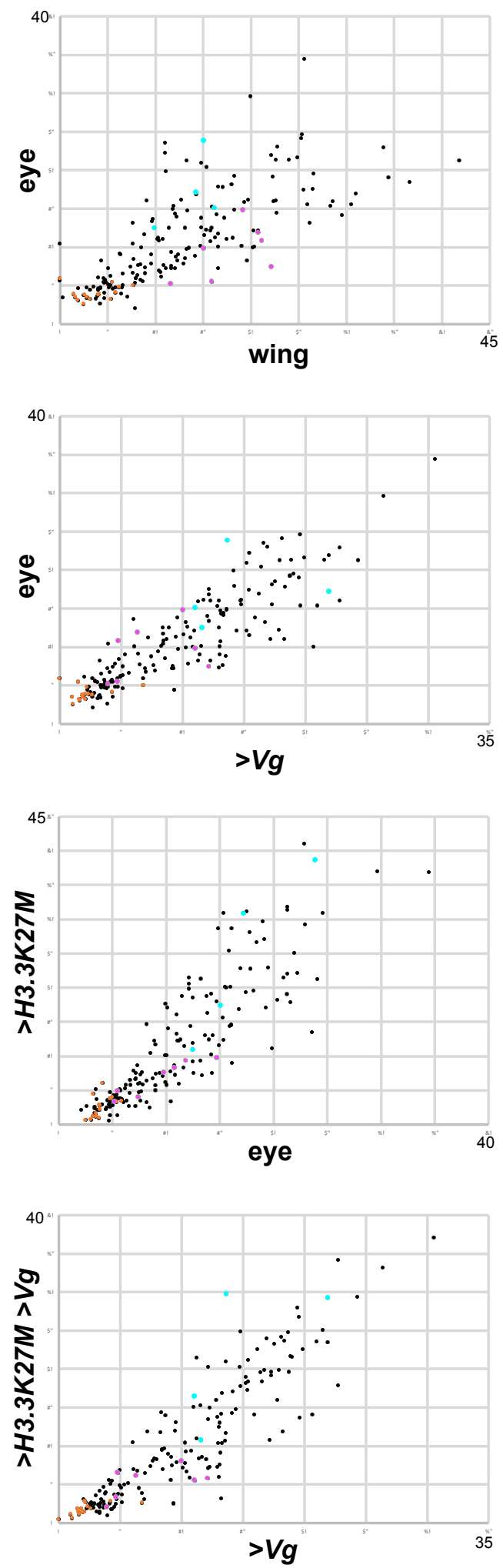

Figure 5. Chromatin profiling of H3K27me3 domains in reprogrammed eye imaginal discs. (A) Chromatin profiling at the ANTP-C H3K27me3 domain in wing and eye imaginal discs. Arrowheads mark the positions of major Polycomb-bound PREs. (B) H3K27me3 profiling spanning the wing-specific $a p$ and eye-specific so and optix genes in wing and eye imaginal discs. (C) Scatterplots of average H3K27me3 signal in 166 domains (black) and 16 background control regions (orange). Domains including eye specification genes are in magenta, and domains with wing specification genes are in blue. (D) Domains ranked by decreasing average H3K27me3 signal in wing and eye imaginal discs. Selected domains spanning eye (magenta), wing (blue) or common domains (grey) are displayed. (E) Average H3K27me3 signal around 700 Polycomb-bound PREs defined from published ChIP-seq profiling [Loubière et al, 2016] within H3K27me3 domains. 
feres with methylation spreading [Harutyunyan et al, 2019; Jain et al, 2020]. Indeed, changes in the pattern of H3K27me3 methylation is apparent at individual domains, such as the ANTP-C (Figure 5A). Here, PREs are still heavily marked with the histone modification, but intervening regions are reduced, consistent with the oncohistone inhibiting spreading of the modification from PREs. We used published sites of Polycomb binding within H3K27me3 domains [Loubière et al, 2016; Supplementary Information] to define the positions of PREs and display H3K27me3 signals around those sites, confirming a consistent loss of methylation surrounding a peak immediately over PREs (Figure 5E). H3K27me3 profiling of eye disc portions co-expressing $\mathrm{Vg}$ and H3.3K27M recapitulate this effect: domains are still present but show reduced spreading of H3K27me3 around PREs (Figure 5E). The one notable change in H3K27 methylation is at the $v g$ gene: ectopic $\mathrm{Vg}$ expression reduces methylation across this domain, but this gene becomes more methylated with oncohistone co-expression (Figure 5D). Thus, oncohistone expression in the eye does not ablate H3K27me3 domains, instead, the genome-wide reduction in methylation affects both eye- and wing-specific domains.

\section{Chromatin profiling of $\mathrm{H} 3 \mathrm{~K} 4 \mathrm{me} 2$ histone modifica- tion in reprogrammed tissues}

We next looked at chromatin profiles of the H3K4me2 histone modification, a marker of active promoters and enhancers. The genome-wide enrichment of $\mathrm{H} 3 \mathrm{~K} 4 \mathrm{me} 2$ at promoters is very similar between wing and eye discs, driven by their similar expression profiles of housekeeping genes (Figure 6A). However, promoters of wing and eye specification transcription factors do show increased $\mathrm{H} 3 \mathrm{~K} 4 \mathrm{me} 2$ signal in the tissue where the gene is active (Figure 6B,C). H3K4me2 signal also identifies which promoter is active between alternative promoters, such as at the ey gene (Figure $6 C)$. We used published mRNA profiling of wing and eye imaginal discs [Naval-Sanchez et al, 2013] to de-
A promoter $\mathrm{H} 3 \mathrm{~K} 4 \mathrm{me} 2$

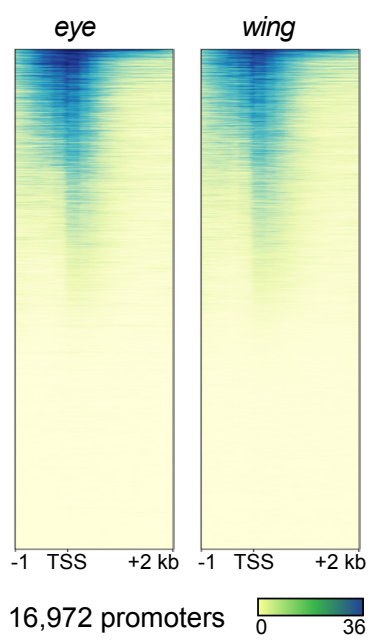

D promoter $\mathrm{H} 3 \mathrm{~K} 4 \mathrm{me} 2$

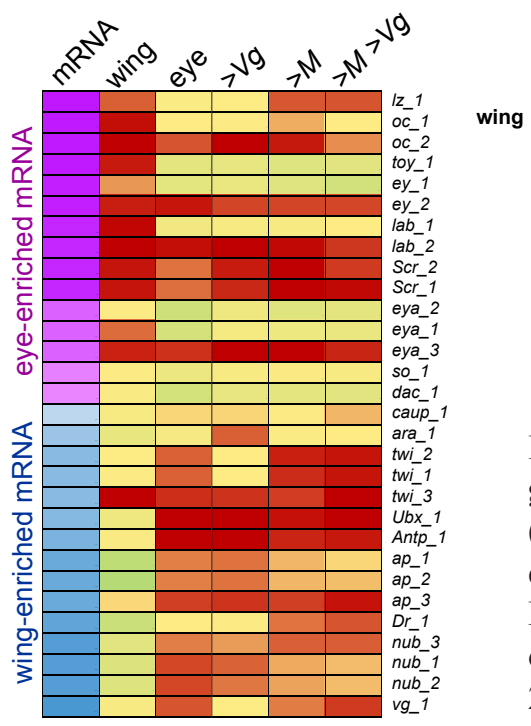

B

C
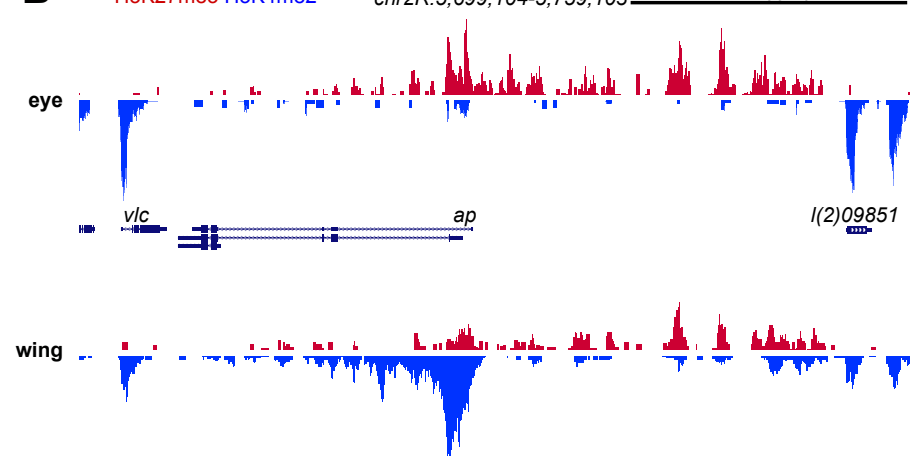

H3K27me3 H3K4me2

chr4:690,682-730,681

$10 \mathrm{~kb}$

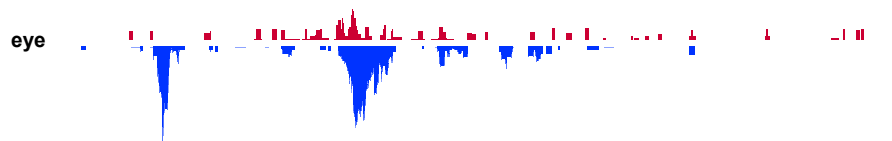

mvo

- ey

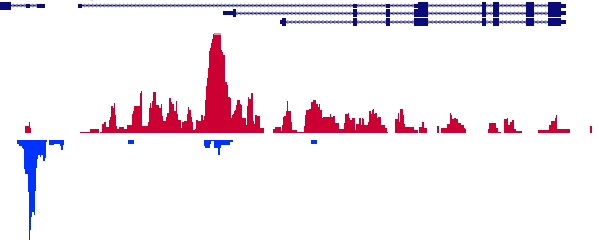

Figure 6. Chromatin profiling of $\mathrm{H} 3 \mathrm{~K} 4 \mathrm{me} 2$ signal at promoters in reprogrammed eye imaginal discs. (A) Heatmaps of $\mathrm{H} 3 \mathrm{~K} 4 \mathrm{me} 2$ signal around promoters in eye and wing imaginal discs. (B,C) H3K27me3 and H3K4me2 features at the wing-specific ap gene (B) and at the eye-specific ey gene $(\mathbf{C})$ in wing and eye imaginal discs. (D) Promoters ranked by decreasing average $\mathrm{H} 3 \mathrm{~K} 4 \mathrm{me} 2$ signal in a $+500 \mathrm{bp}$ around the TSS in wing and eye imaginal discs. Selected promoters of differentially-expressed genes defined from published RNA-seq profiling [Naval-Sanchez et al, 2013] are displayed. Alternative promoters for these genes are numbered. 
fine differentially-transcribed genes between these tissues, identifying 804 genes up-regulated in eye discs and 174 up-regulated in wing discs, and rank-ordered the amount of $\mathrm{H} 3 \mathrm{~K} 4 \mathrm{me} 2$ signal in a $1 \mathrm{~kb}$ window centered on annotated gene promoters in the Drosophila genome (Supplementary Information). In most cases promoters gain $\mathrm{H} 3 \mathrm{~K} 4 \mathrm{me} 2$ signal in the tissue where they are active, and the few exceptions appear to be the unused promoter of alternative TSSs (Figure 6D). Thus, the activation of specification genes is associated with both increases in promoter $\mathrm{H} 3 \mathrm{~K} 4 \mathrm{me} 2$ signal reductions in domain $\mathrm{H} 3 \mathrm{~K} 27 \mathrm{me} 3$ signals.

We then profiled the H3K4me2 modification in dissected eye discs from larvae expressing $\mathrm{Vg}$. Promoter signals in these discs show slight reduction in H3K4me2 at the promoters of multiple eye specification genes such as oc, Scr, ey, eya, and so (Figure 6D). These changes are not as dramatic as the loss of H3K4me2 signal in wing discs, perhaps due to the mosaicism of this sample (Figure 1E) or to incomplete activation in transformed cells. However, some wing-specific genes in Vg-expressing eye discs do show gain in $\mathrm{H} 3 \mathrm{~K} 4 \mathrm{me} 2$ signal at gene promoters, such as at twi and at vg itself (Figure 6D). These limited promoter changes indicate that reprogramming of the eye by ectopic $\mathrm{Vg}$ is driven by the activation of a subset of genes involved in wing specification.

We then profiled $\mathrm{H} 3 \mathrm{~K} 4 \mathrm{me} 2$ histone modifications in eye discs expressing the H3.3K27M oncohistone. Expression of the oncohistone has little effect on H3K4me2 marks at active promoters in eye discs (Figure 6D; Supplementary Figure 1F). Co-expression of H3.3K27M and $\mathrm{Vg}$ also has little effect on promoter H3K4me2 marks, which is expected since ectopic $\mathrm{Vg}$ expression also has limited effects. The largest change is at the $v g$ promoter itself, where ectopic $\mathrm{Vg}$ expression increases $\mathrm{H} 3 \mathrm{~K} 4 \mathrm{me} 2$ signal at this promoter, but co-expression of $\mathrm{Vg}$ and H3.3K27M prevent this gain (Figure 6D). Ectopic $\mathrm{Vg}$ expression also causes slight reductions of $\mathrm{H} 3 \mathrm{~K} 4 \mathrm{me} 2$ signal at the ey and eya promoters, and these signals increase when $\mathrm{Vg}$ and the oncohistone are co-expressed (Figure 6D). These changes are consistent with the idea that $\mathrm{Vg}$ expression inhibits expression of eye specification genes during reprogramming, but oncohistone co-expression relieves this inhibition.

\section{H3K27M and Vg co-expression imitates PRC1 mutants}

Tissue reprogramming has been associated with a number of components in the Polycomb silencing system [Grossniklaus \& Paro, 2014]. H3K27 trimethylation is catalyzed by the $E(z)$ histone modifying enzyme, a component of the Polycomb Repressive Complex 2,

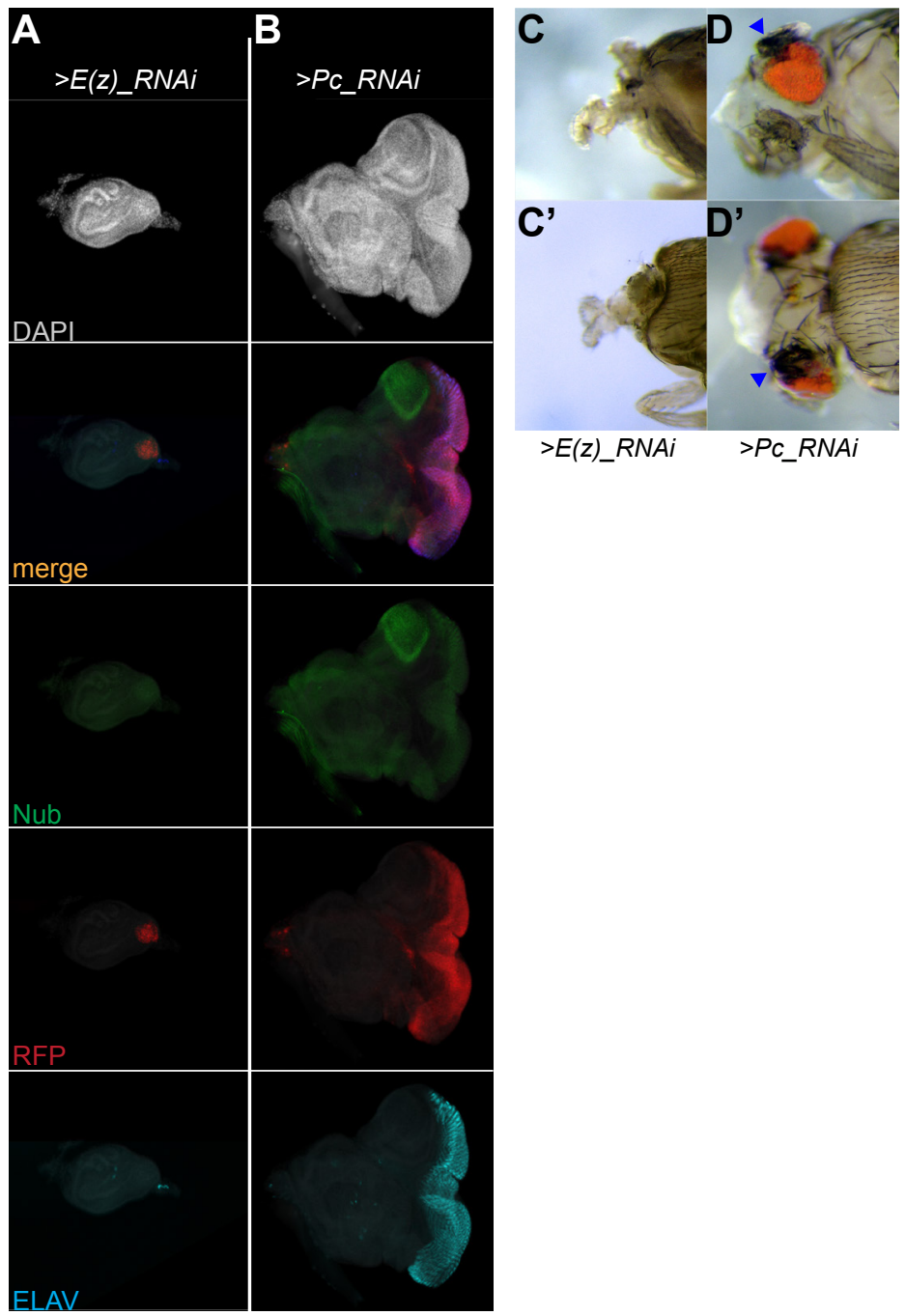

Figure 7. Effects of reduced PRC1 and PRC2 on direct reprogramming and cell proliferation. $(\mathbf{A}, \mathbf{B})$ Eye-antennal discs with eyGAL-induced expression of RFP and RNAi constructs directed against $E(z)(\mathbf{A})$ or $P c(\mathbf{B})$ transcripts. Both discs are immunostained for the wing-specific Nub protein and the photoreceptor marker ELAV. The eye and antennal portions of discs are greatly reduced with $E(z)$ knockdown, while $P c$ knockdown results in overgrowth of the eye portion and expression of Nub at the dorsal edge of the disc. (C,D) Heads of dissected dying pharate pupae with $E(z)$ knockdown $(\mathbf{C})$ or $P c$ knockdown (D). Loss of $E(z)$ ablates all tissue derived from the eye-antennal disc including the head capsule and eyes, without affecting mouthparts. Loss of Pc induces ectopic wing-like structures (blue arrowheads) at the dorsal edges of eyes.

while the Polycomb Repressive Complex 1 (PRC1) complex binds the H3K27me3 mark on nucleosomes [Di Croce \& Helin, 2013]. Mutation of PRC1 components result in overgrowth of imaginal discs, but mutations in PRC2 components inhibit cell growth [Classen et al, 2009; Loubière et al, 2016], implying that the two complexes have non-overlapping functions. We examined the roles of PRC1 and PRC2 in reprogramming of the eye. A previous study characterized eyGAL-induced knock-down of PRC1 and PRC2 components 
[Zhu et al, 2018], which we repeated here. Knocking down the PRC2 histone methyltransferase $E(z)$ inhibits proliferation, resulting in near elimination of the eye portion of imaginal discs (Figure 7A) and lethality, where dying animals lack all head structures derived from the eye-antennal imaginal disc (Figure 7C). Thus, growth inhibition by H3.3K27M expression resembles intermediate reduction of the $\mathrm{E}(\mathrm{z})$ enzyme, consistent with the dominant inhibition of this enzyme by the oncohistone.

Eye-specific knockdown of Polycomb derepresses the Antp HOX gene, reprogramming part of the eye to winglike tissue and inducing overgrowth in the disc [Zhu et al, 2018]. This is also lethal, however knockdown eye discs are often expanded with an outgrowth on one side of the disc [Zhu et al, 2018] and (Figure 7B). Dying animals with Polycomb knockdown show wing-like outgrowths on the dorsal side of the eye [Zhu et al, 2018] (Figure 7D). Polycomb loss efficiently induces wing tissue, since the wing factor Nub is expressed at high levels in these discs (Figure 7B). The location of high Nub expression coincides with a region that appears to be predisposed to transformation by high expression of common signalling factors [Maves \& Schubiger, 1999; Zhu et al, 2018]. Thus, effects of PRC1 loss actually resemble those of $\mathrm{Vg}$ and $\mathrm{H} 3.3 \mathrm{~K} 27 \mathrm{M}$ co-expression, implying that the loss of chromatin silencing and mis-expression of a determinative transcription factors synergizes to drive tissue overgrowth.

\section{Discussion}

The idea that cell fate programs are reinforced by chromatin silencing of alternative pathways implies that reducing epigenetic barriers that restrict cell fates will stimulate cell fate transformations. We find the opposite - using ectopic expression of the $\mathrm{Vg}$ master regulator factor, we find that compromised silencing does not enhance transformation of the eye; instead cells of the eye disc hyperproliferate. It is startlingly simple to create overgrowth tumors in the Drosophila developing eye: expression of only two proteins - the H3.3K27M oncohistone and a transcription factor - are sufficient. Commitment to a developmental fate requires both the expression of genes for determinative transcription factors and the silencing of genes for alternative fates. Coordinated activation and silencing may shape and stabilize developmental trajectories. Our results highlight that chromatin silencing is essential for transcription factor-induced developmental reprogramming. Cell identity in the Drosophila eye is determined by a network of self-reinforcing transcription factors. To reprogram this tissue expression of $\mathrm{Vg}$ must both induce wing specification genes and silence eye-specifying factors. Surprisingly, inhibition of H3K27 methylation does not enhance reprogramming, implying that the activation of silenced wing specification genes is not limiting. Instead, our results argue that H3K27me3-mediated silencing of eye-specific factors is needed for successful reprogramming. This requirement may result from the inducing $\mathrm{Vg}$ in a setting where the eye determination program has already been established. Further, the differentiation of retinal cells even when $\mathrm{Vg}$ is expressed indicates that eye determination factors must be dominant to wing specification factors, similar to what has been observed after tissue damage in Drosophila [Maves \& Schubiger, 2003]. Intriguingly, overexpression of the histone gene transcription factor Wge can also drive eye-to-wing reprogramming, but this case requires chromatin silencing mediated by the histone H3K9 methyltransferase Su(var)3-9 [Ozawa et al, 2016; Masuko et al, 2018]. Thus, an established developmental program may be silenced by either H3K27me3- or H3K9me3-mediated pathways during reprogramming.

Why does inhibiting reprogramming with the H3K27M oncohistone result in neoplastic growth? Genetic studies in mammalian systems have demonstrated that H3K27M oncohistones are not sufficient to induce tumorigenesis on their own [Mohammad et al, 2017]. Instead, secondary mutations are necessary, and the low mutational burdens of H3K27M-bearing cancers in patients implies that specific mutations are sufficient for malignancy. Some mutations are in classical tumor suppressor genes like TP53, thereby enhancing malignancy. In pediatric midline gliomas, additional secondary mutations are often in specific signaling receptors such as PDGFRA or ACVR1 [Schwartzentruber et al, 2012; Fontebasso et al, 2014; Buczkowicz et al, 2014; Mackay et al, 2017; Wu et al, 2014], and the hyperactivation of developmental signalling probably induces the mis-expression of developmental transcription factors. Co-expression of the H3.3K27M oncohistone and $\mathrm{Vg}$ appears to imitate this effect. $\mathrm{Vg}$ both promotes a wing cell fate and stimulates cell growth [Delanoue et al, 2004], thus suppressing reprogramming may result in unrestrained proliferation. While mutation of the four $\mathrm{Vg}$ homologs in humans is not observed in gliomas, mis-expression of three paralogs are associated with other cancers [Yamaguchi, 2020]. More generally, that simply mis-expressing a developmental transcription factor and an oncohistone stimulates proliferation suggests that other transcription factors might also do so, explaining the cell-type- and stage-restriction of oncohistone-driven cancers.

It is striking that mutations in PRC1 components stimu- 
late uncontrolled proliferation, while mutation of PRC2 components do not [Classen et al, 2009; Loubière et al, 2016]. These two complexes normally work together to silence domains in genomes, but PRC1 also regulates gene expression of some developmental targets [Aranda et al, 2015; Loubière et al, 2020]. Our results suggest that mutations in PRC1 components both lose chromatin silencing and mis-express a developmental regulator, driving cell proliferation.

\section{Methods}

Fly strains: All crosses were performed at $25^{\circ} \mathrm{C}$. All mutations and chromosomal rearrangements used here are described in Flybase (http://www.flybase.org) and sources are listed in the Key Resources Table. The eyGAL4-3-8 driver was used for all experiments shown here, although identical results were obtained with other eyGAL4 constructs and insertions.

Transgenes: Inducible H3.3 constructs were constructed by cloning the UASp promoter and the His3.3A ORF into the pKC27mw transformation vector [Okluski et al, 2011] (a gift from L. Ringrose, Humboldt-Univerität zu Berlin), and then used site-directed mutagenesis $\mathrm{PCR}$ to make the K27M and K27R mutated versions. Each plasmid was injected into y M[vas-int.Dm]ZH-2A $w$; P[attP,y+,w3'NIE-260B embryos by Bestgene Inc (Chino Hills, CA). This line contains two landing sites [Green et al, 2014]; integrants at the 25C landing site were used in this study.

Imaging imaginal discs: Imaginal discs from late 3rd instar larvae were dissected and fixed for 10 minutes in $4 \%$ formaldehyde/PBST (PBS with $0.1 \%$ triton-X100), and then incubated twice in $0.3 \%$ sodium deoxycholate/PBST for 20' each. Samples were incubated with primary antiserum diluted in PBST supplemented with $10 \%$ goat serum at $4^{\circ}$ overnight, and finally with fluorescently labeled secondary antibodies (1:200 dilution, Jackson ImmunoResearch). All tissues were stained with $0.5 \mu \mathrm{g} / \mathrm{mL}$ DAPI/PBS, mounted in $80 \%$ glycerol on slides, and imaged by epifluorescence on an EVOS FL Auto 2 inverted microscope (Thermo Fisher Scientific) with a 10X objective. Pseudo-colored images were adjusted and composited in Adobe Photoshop and Adobe Illustrator. All antibodies used are listed in the Key Resources Table.

Imaging adult eyes: Adults were euthanized in a freezer and then imaged using a Sony digital camera mounted on a Nikon SMZ1500 stereomicroscope. Images were color-corrected with Adobe Photoshop and composited in Adobe Illustrator.

Chromatin profiling and sequencing: We dissected imaginal discs from 3rd instar larvae in Wash+ buffer
(20 mM HEPES pH 7.5, 150 mM NaCl, 0.5 mM spermidine with Roche cOmplete protease inhibitor). We used 4 wing imaginal discs and 6 eye-antennal imaginal discs for each chromatin profiling experiment. Experiments were performed in duplicate and in parallel to minimize technical variation. We used immuno-tethered CUT\&Tag chromatin profiling [Kaya-Okur et al, 2020] with antibodies to histone H3K27me3 (C36B11, Cell Signalling Technology) and to histone H3K4me2 (13-0027, Epicypher) modifications. To adapt CUT\&Tag for whole tissues, we coated imaginal discs with BioMag Plus Concanavalin-A-conjugated magnetic beads (ConA beads, Polysciences, Inc) in 8-tube PCR strips, and exchanged solutions on a magnetic stand (MSR812, Permagen). Tissues were incubated with primary antibody in dbe+ buffer $(20 \mathrm{mM}$ HEPES pH 7.5, $150 \mathrm{mM} \mathrm{NaCl}, 0.5 \mathrm{mM}$ spermidine, 2 mM EDTA, 1\% BSA, 0.05\% digitonin with Roche cOmplete protease inhibitor) overnight at $4^{\circ} \mathrm{C}$, incubated with secondary antibody in dbe+ buffer for 1 hour at room temperature, and then incubated with proteinA-Tn5 loaded with adapters in 300Wash+ buffer (20 mM HEPES pH 7.5, 300 mM NaCl, 0.5 mM spermidine with Roche cOmplete protease inhibitor) for 1 hour. After one wash with 300 Wash+ buffer, samples were incubated in 300 Wash+ buffer supplemented with 10 $\mathrm{mM} \mathrm{MgCl} 2$ for 1 hour at $37^{\circ}$ to tagment chromatin. Reactions were stopped by addition of SDS to $0.16 \%$ and protease $\mathrm{K}$ to $0.3 \mathrm{mg} / \mathrm{mL}$, incubated at $58^{\circ}$ for 1 hour, and DNA was purified by phenol:chloroform extraction and ethanol precipitation.

Libraries were prepared as described [Kaya-Okur et al, 2020], with 14 cycles of PCR with 10 second combined annealing and extension for enrichment of short DNA fragments. Libraries were sequenced for 25 cycles in paired-end mode on the Illumina HiSeq 2500 platform at the Fred Hutchinson Cancer Research Center Genomics Shared Resource. Paired-end reads were mapped to release $\mathrm{r} 6.30$ of the $\mathrm{D}$. melanogaster genome obtained from FlyBase using Bowtie2, and to the E coli genome for spike-in normalization. A step-bystep protocol is posted: https://www.protocols.io/view/ cut-tag-with-drosophila-tissues-bnx5mfq6

Data analysis: Track screenshots were produced using the UCSC Genome browser (http://genome.ucsc.edu) [Kent et al, 2002]. We manually annotated H3K27me3 domains as enriched blocks in either wing or eye imaginal discs, or in profiling of larval brains [Ahmad \&Spens, 2019], and are listed in Supplementary Information. We used EPDnew for promoter locations in dm6 genome assembly [Dreos et al, 2015], and FB 2020_03 for gene annotations [Gramates et al, 2017]. 

available under aCC-BY-NC-ND 4.0 International license.

Analysis and display was done using deeptools in Galaxy (multibigwigsummary, computematrix, plotheatmap, plotPCA) and MS Excel. Differential gene expression and chromatin feature analysis was done using degust (degust.erc.monash.edu).

Detailed protocol at protocols.io: https://www.protocols.io/view/cut-tag-with-drosophila-tissues-bnx $5 \mathrm{mfq} 6$

\section{GEO link:}

In process

\section{Acknowledgements}

We thank Jay F. Sarthy and Derek H. Janssens for comments. Stocks obtained from the Bloomington Drosophila Stock Center (NIH P40OD018537) and antibodies obtained from the Developmental Studies Hybridoma Bank (created by the NICHD of the $\mathrm{NIH}$ ) were used in this study. This work was funded by the $\mathrm{NIH}$ (R01HG010492, SH).

\section{References}

Ahmad K, Spens AE (2019). Separate Polycomb Response Elements control chromatin state and activation of the vestigial gene. PLoS Genet. 15:e1007877. doi: 10.1371/journal.pgen.1007877. PMID: 31425502.

Aranda S, Mas G, Di Croce L (2015). Regulation of gene transcription by Polycombproteins. Sci Adv. 1:e1500737. doi: 10.1126/sciadv.1500737. PMID: 26665172.

Averof M, Cohen SM (1997). Evolutionary origin of insect wings from ancestral gills. Nature 385:627-30. PMID: 9024659.

Bechet D, Gielen GG, Korshunov A, Pfister SM, Rousso $C$, Faury D, Fiset $P O$, Benlimane $N$, Lewis $P W$, Lu C, David Allis C, Kieran MW, Ligon KL, Pietsch T, Ellezam B, Albrecht S, Jabado N (2014). Specific detection of methionine 27 mutation in histone 3 variants (H3K27M) in fixed tissue from high-grade astrocytomas. Acta Neuropathol. 128:733-41. doi: 10.1007/ s00401-014-1337-4. PMID: 25200321.

Bemer M, Grossniklaus U (2012). Dynamic regulation of Polycomb group activity during plant development. Curr Opin Plant Biol. 15:523-9. doi: 10.1016/j. pbi.2012.09.006. PMID: 22999383.

Bender S, Tang Y, Lindroth AM, Hovestadt V, Jones DT, Kool M, Zapatka M, Northcott PA, Sturm D, Wang W, Radlwimmer B, Højfeldt JW, Truffaux N, Castel D, Schubert S, Ryzhova M, Seker-Cin H, Gronych J, Johann PD, Stark S, Meyer J, Milde T, et al (2013). Reduced H3K27me3 and DNA hypomethylation are major drivers of gene expression in K27M mutant pediatric high-grade gliomas. Cancer Cell 24:660-72. doi: 10.1016/j.ccr.2013.10.006. PMID: 24183680.

Blochlinger K, Bodmer R, Jan LY, Jan YN (1990). Patterns of expression of cut, a protein required for external sensory organ development in wild-type and cut mutant Drosophila embryos. Genes Dev.4:132231. PMID: 1977661.

Buczkowicz P, Hoeman C, Rakopoulos P, Pajovic $S$, Letourneau L, Dzamba M, Morrison A, Lewis P, Bouffet E, Bartels U, Zuccaro J, Agnihotri S, Ryall S, Barszczyk M, Chornenkyy Y, Bourgey M, Bourque G, Montpetit A, Cordero F, Castelo-Branco P, Mangerel J, Tabori U, et al (2014). Genomic analysis of diffuse intrinsic pontine gliomas identifies three molecular subgroups and recurrent activating ACVR1 mutations. Nat Genet. 46:451-6. doi: 10.1038/ng.2936. PMID: 24705254.

Chan KM, Fang D, Gan H, Hashizume R, Yu C, Schroeder M, Gupta N, Mueller S, James CD, Jenkins R, Sarkaria J, Zhang Z (2013). The histone H3.3K27M mutation in pediatric glioma reprograms $\mathrm{H} 3 \mathrm{~K} 27$ methylation and gene expression. Genes Dev. 27:985-90. doi: 10.1101/gad.217778.113. PMID: 23603901.

Classen AK, Bunker BD, Harvey KF, Vaccari T, Bilder D (2009). A tumor suppressor activity of Drosophila Polycomb genes mediated by JAK-STAT signaling. Nat Genet. 41:1150-5. doi: 10.1038/ng.445. PMID: 19749759.

Delanoue R, Legent K, Godefroy N, Flagiello D, Dutriaux A, Vaudin P, Becker JL, Silber J (2004). The Drosophila wing differentiation factor vestigial-scalloped is required for cell proliferation and cell survival at the dorso-ventral boundary of the wing imaginal disc. Cell Death Differ. 11:110-22. PMID: 14526388.

Di Croce L, Helin K (2013). Transcriptional regulation by Polycomb group proteins. Nat Struct Mol Biol. 20:1147-55. doi: 10.1038/nsmb.2669. PMID: 24096405.

Dreos R, Ambrosini G, Périer RC, Bucher P (2015). The Eukaryotic Promoter Database: expansion of EPDnew and new promoter analysis tools. Nucleic Acids Res. 43:D92-6. doi: 10.1093/nar/gku1111. PMID: 25378343.

Fons NR, Sundaram RK, Breuer GA, Peng S, McLean RL, Kalathil AN, Schmidt MS, Carvalho DM, Mackay A, Jones C, Carcaboso ÁM, Nazarian J, Berens ME, Brenner C, Bindra RS (2019). PPM1D mutations silence NAPRT gene expression and confer NAMPT inhibitor sensitivity in glioma. Nat Commun. 10:3790. 
bioRxiv preprint doi: https://doi.org/10.1101/2020.11.10.375881; this version posted November $11,2020$. The copyright holder for this preprint (which was not certified by peer review) is the author/funder, who has granted bioRxiv a license to display the preprint in perpetuity. It is made available under aCC-BY-NC-ND 4.0 International license.

doi: 10.1038/s41467-019-11732-6. PMID: 31439867.

Fontebasso AM, Papillon-Cavanagh S, Schwartzentruber J, Nikbakht H, Gerges N, Fiset PO, Bechet D, Faury D, De Jay N, Ramkissoon LA, Corcoran A, Jones DT, Sturm D, Johann P, Tomita T, Goldman S, Nagib M, Bendel A, Goumnerova L, Bowers DC, Leonard JR, Rubin JB, et al (2014). Recurrent somatic mutations in ACVR1 in pediatric midline high-grade astrocytoma. Nat Genet. 46:462-6. doi: 10.1038/ ng.2950. PMID: 24705250.

Graf T (2011). Historical origins of transdifferentiation and reprogramming. Cell Stem Cell 9:504-16. doi: 10.1016/j.stem.2011.11.012. PMID: 22136926.

Gramates LS, Marygold SJ, Santos GD, Urbano JM, Antonazzo G, Matthews BB, Rey AJ, Tabone CJ, Crosby MA, Emmert DB, Falls K, Goodman JL, Hu Y, Ponting L, Schroeder AJ, Strelets VB, Thurmond J, Zhou P et al (2017). FlyBase at 25: looking to the future. Nucleic Acids Res. 45:D663-D671. doi: 10.1093/ nar/gkw1016. PMID: 27799470.

Green EW, Fedele G, Giorgini F, Kyriacou CP (2014). A Drosophila RNAi collection is subject to dominant phenotypic effects. Nat Methods 11:222-3. doi: 10.1038/nmeth.2856. PMID: 24577271.

Grossniklaus U, Paro R (2014). Transcriptional silencing by polycomb-group proteins. Cold Spring Harb Perspect Biol. 6:a019331. doi: 10.1101/cshperspect. a019331. PMID: 25367972.

Harrison DA, Binari R, Nahreini TS, Gilman M, Perrimon N (1995). Activation of a Drosophila Janus kinase (JAK) causes hematopoietic neoplasia and developmental defects. EMBO J. 14:2857-65. PMID: 7796812.

Harutyunyan AS, Krug B, Chen H, Papillon-Cavanagh S, Zeinieh M, De Jay N, Deshmukh S, Chen CCL, Belle J, Mikael LG, Marchione DM, Li R, Nikbakht H, Hu B, Cagnone G, Cheung WA, Mohammadnia A, Bechet D, Faury D, McConechy MK, Pathania M, Jain SU, et al (2019). H3K27M induces defective chromatin spread of PRC2-mediated repressive H3K27me2/ me 3 and is essential for glioma tumorigenesis.

Nat Commun. 10:1262. doi: 10.1038/s41467-01909140-x. PMID: 30890717.

Hazelett DJ, Bourouis M, Walldorf U, Treisman JE (1998). decapentaplegic and wingless are regulated by eyes absent and eyegone and interact to direct the pattern of retinal differentiation in the eye disc. Development 125:3741-51. PMID: 9716539.
Herz HM, Morgan M, Gao X, Jackson J, Rickels R, Swanson SK, Florens L, Washburn MP, Eissenberg JC, Shilatifard A (2014). Histone H3 lysine-to-methionine mutants as a paradigm to study chromatin signaling. Science 345:1065-70. doi: 10.1126/science.1255104. PMID: 25170156.

Ives PT (1956). New mutants report. Drosophila Information Service 30:72-73.

Jain SU, Rashoff AQ, Krabbenhoft SD, Hoelper D, Do TJ, Gibson TJ, Lundgren SM, Bondra ER, Deshmukh $\mathrm{S}$, Harutyunyan AS, Juretic N, Jabado N, Harrison MM, Lewis PW (2020). H3 K27M and EZHIP Impede H3K27-Methylation Spreading by Inhibiting Allosterically Stimulated PRC2. Mol Cell pii: S10972765(20)30680-8. doi: 10.1016/j.molcel.2020.09.028. PMID: 33049227.

Justin N, Zhang Y, Tarricone C, Martin SR, Chen S, Underwood E, De Marco V, Haire LF, Walker PA, Reinberg D, Wilson JR, Gamblin SJ (2016). Structural basis of oncogenic histone H3K27M inhibition of human polycomb repressive complex 2. Nat Commun. 7:11316. doi: 10.1038/ncomms11316. PMID: 27121947.

Kaya-Okur HS, Wu SJ, Codomo CA, Pledger ES, Bryson TD, Henikoff JG, Ahmad K, Henikoff S (2019). CUT\&Tag for efficient epigenomic profiling of small samples and single cells. Nat Commun. 10:1930. doi: 10.1038/s41467-019-09982-5. PMID: 31036827.

Kaya-Okur HS, Janssens DH, Henikoff JG, Ahmad K, Henikoff S (2020). Efficient low-cost chromatin profiling with CUT\&Tag. Nat Protoc. 15:3264-3283. doi: 10.1038/s41596-020-0373-x. PMID: 32913232.

Kent WJ, Sugnet CW, Furey TS, Roskin KM, Pringle TH, Zahler AM, Haussler D (2002). The human genome browser at UCSC. Genome Res. 12:996-1006. PMID: 12045153.

Kim J, Sebring A, Esch JJ, Kraus ME, Vorwerk K, Magee J, Carroll SB (1996). Integration of positional signals and regulation of wing formation and identity by Drosophila vestigial gene. Nature 382:133-8. PMID: 8700202.

Lanzuolo C, Orlando V (2012). Memories from the polycomb group proteins. Annu Rev Genet. 46:56189. doi: 10.1146/annurev-genet-110711-155603. PMID: 22994356.

Laprell F, Finkl K, Müller J (2017). Propagation of Polycomb-repressed chromatin requires sequence-specific recruitment to DNA. Science 356:85- 
bioRxiv preprint doi: https://doi.org/10.1101/2020.11.10.375881; this version posted November $11,2020$. The copyright holder for this preprint (which was not certified by peer review) is the author/funder, who has granted bioRxiv a license to display the preprint in perpetuity. It is made available under aCC-BY-NC-ND 4.0 International license.

88. doi: 10.1126/science.aai8266. PMID: 28302792.

Lewis PW, Müller MM, Koletsky MS, Cordero F, Lin S, Banaszynski LA, Garcia BA, Muir TW, Becher OJ, Allis CD (2013). Inhibition of PRC2 activity by a gain-offunction $\mathrm{H} 3$ mutation found in pediatric glioblastoma. Science 340:857-61. doi: 10.1126/science.1232245. PMID: 23539183.

Lewis ZA (2017). Polycomb Group Systems in Fungi: New Models for Understanding Polycomb Repressive Complex 2. Trends Genet. 33:220-231. doi: 10.1016/j. tig.2017.01.006. PMID: 28196760.

Loubière $V$, Delest $A$, Thomas $A$, Bonev $B$, Schuettengruber B, Sati S, Martinez AM, Cavalli G (2016). Coordinate redeployment of PRC1 proteins suppresses tumor formation during Drosophila development. Nat Genet. 48:1436-1442. doi: 10.1038/ng.3671. PMID: 27643538.

Loubiere V, Papadopoulos GL, Szabo Q, Martinez AM, Cavalli G (2020). Widespread activation of developmental gene expression characterized by PRC1-dependent chromatin looping. Sci Adv. 6:eaax4001. doi: 10.1126/sciadv.aax4001. PMID: 31950077.

Mackay A, Burford A, Carvalho D, Izquierdo E, Fazal-Salom J, Taylor KR, Bjerke L, Clarke M, Vinci M, Nandhabalan M, Temelso S, Popov S, Molinari V, Raman P, Waanders AJ, Han HJ, Gupta S, Marshall L, Zacharoulis S, Vaidya S, Mandeville HC, Bridges LR, et al (2017). Integrated Molecular Meta-Analysis of 1,000 Pediatric High-Grade and Diffuse Intrinsic Pontine Glioma. Cancer Cell 32:520-537.e5. doi: 10.1016/j.ccell.2017.08.017. PMID: 28966033.

Mardon G, Solomon NM, Rubin GM (1994). dachshund encodes a nuclear protein required for normal eye and leg development in Drosophila. Development 120:3473-86. PMID: 7821215.

Masuko K, Fuse N, Komaba K, Katsuyama T, Nakajima R, Furuhashi H, Kurata S (2018). winged eye Induces Transdetermination of Drosophila Imaginal Disc by Acting in Concert with a Histone Methyltransferase, Su(var)3-9. Cell Rep. 22:206-217. doi: 10.1016/j. celrep.2017.11.105. PMID: 29298422.

Maves L, Schubiger G (1999). Cell determination and transdetermination in Drosophila imaginal discs. Curr Top Dev Biol. 43:115-51. PMID: 9891885.

Maves L, Schubiger G (2003). Transdetermination in Drosophila imaginal discs: a model for understanding pluripotency and selector gene maintenance. Curr
Opin Genet Dev. 13:472-9. PMID: 14550411.

Miyagi S, Saito T, Mizutani K, Masuyama N, Gotoh Y, Iwama A, Nakauchi H, Masui S, Niwa H, Nishimoto M, Muramatsu M, Okuda A (2004). The Sox-2 regulatory regions display their activities in two distinct types of multipotent stem cells. Mol Cell Biol. 24:4207-20. PMID: 15121842.

Mohammad F, Weissmann S, Leblanc B, Pandey DP, Højfeldt JW, Comet I, Zheng C, Johansen JV, Rapin N, Porse BT, Tvardovskiy A, Jensen ON, Olaciregui NG, Lavarino C, Suñol M, de Torres C, Mora J, Carcaboso AM, Helin K (2017). EZH2 is a potential therapeutic target for H3K27M-mutant pediatric gliomas. Nat Med. 23:483-492. doi: 10.1038/nm.4293. PMID: 28263309.

Mohammad F, Helin K (2017). Oncohistones: drivers of pediatric cancers. Genes Dev. 31:2313-2324. doi: 10.1101/gad.309013.117. PMID: 29352018.

Naval-Sánchez M, Potier D, Haagen L, Sánchez M, Munck S, Van de Sande B, Casares F, Christiaens $V$, Aerts S (2013). Comparative motif discovery combined with comparative transcriptomics yields accurate targetome and enhancer predictions. Genome Res. 23:74-88. doi: 10.1101/gr.140426.112. PMID: 23070853.

O'Neill EM, Rebay I, Tjian R, Rubin GM (1994). The activities of two Ets-related transcription factors required for Drosophila eye development are modulated by the Ras/MAPK pathway. Cell 78:137-47. PMID: 8033205.

Okulski H, Druck B, Bhalerao S, Ringrose L (2011). Quantitative analysis of polycomb response elements (PREs) at identical genomic locations distinguishes contributions of PRE sequence and genomic environment. Epigenetics Chromatin 4:4. doi: 10.1186/17568935-4-4. PMID: 21410956.

Ozawa N, Furuhashi H, Masuko K, Numao E, Makino T, Yano T, Kurata S (2016). Organ identity specification factor WGE localizes to the histone locus body and regulates histone expression to ensure genomic stability in Drosophila. Genes Cells 21:442-56. doi: 10.1111/gtc.12354. PMID: 27145109.

Pathania M, De Jay N, Maestro N, Harutyunyan AS, Nitarska J, Pahlavan P, Henderson S, Mikael LG, Richard-Londt A, Zhang Y, Costa JR, Hébert S, Khazaei S, Ibrahim NS, Herrero J, Riccio A, Albrecht S, Ketteler R, Brandner S, Kleinman CL, Jabado N, Salomoni P (2017). H3.3(K27M) Cooperates with Trp53 Loss and PDGFRA Gain in Mouse Embryonic Neu- 
bioRxiv preprint doi: https://doi.org/10.1101/2020.11.10.375881; this version posted November $11,2020$. The copyright holder for this preprint (which was not certified by peer review) is the author/funder, who has granted bioRxiv a license to display the preprint in perpetuity. It is made available under aCC-BY-NC-ND 4.0 International license.

ral Progenitor Cells to Induce Invasive High-Grade Gliomas. Cancer Cell 32:684-700.e9. doi: 10.1016/j. ccell.2017.09.014. PMID: 29107533.

Pengelly AR, Copur Ö, Jäckle H, Herzig A, Müller J (2013). A histone mutant reproduces the phenotype caused by loss of histone-modifying factor Polycomb. Science 339:698-9. doi: 10.1126/science.1231382. PMID: 23393264.

Perino M, Veenstra GJ (2016). Chromatin Control of Developmental Dynamics and Plasticity. Dev Cell 38:610-20. doi: 10.1016/j.devcel.2016.08.004. PMID: 27676434.

Perkins LA, Holderbaum L, Tao R, Hu Y, Sopko R, McCall K, Yang-Zhou D, Flockhart I, Binari R, Shim HS, Miller A, Housden A, Foos M, Randkelv S, Kelley C, Namgyal P, Villalta C, Liu LP, Jiang X, Huan-Huan Q, Wang X, Fujiyama A, et al (2015). The Transgenic RNAi Project at Harvard Medical School: Resources and Validation. Genetics 201:843-52. doi: 10.1534/ genetics.115.180208. PMID: 26320097.

Piunti A, Hashizume R, Morgan MA, Bartom ET, Horbinski CM, Marshall SA, Rendleman EJ, Ma Q, Takahashi YH, Woodfin AR, Misharin AV, Abshiru NA, Lulla RR, Saratsis AM, Kelleher NL, James CD, Shilatifard A (2017). Therapeutic targeting of polycomb and BET bromodomain proteins in diffuse intrinsic pontine gliomas. Nat Med. 23:493-500. doi: 10.1038/nm.4296. PMID: 28263307.

Powell DR (2018). Degust: interactive RNA-seq analysis. Zenodo http://doi.org/10.5281/zenodo.3501067.

Ramírez F, Dundar F, Diehl S, Gruning BA, Manke T (2016). deepTools2: a next generation web server for deep-sequencing data analysis. Nucleic Acids Research 44, W160-W165.

Ruiz-Losada M, Blom-Dahl D, Córdoba S, Estella C (2018). Specification and Patterning of Drosophila Appendages. J Dev Biol. 6. pii: E17. doi: 10.3390/ jdb6030017. PMID: 30011921.

Sarkissian T, Timmons A, Arya R, Abdelwahid E, White K (2014). Detecting apoptosis in Drosophila tissues and cells. Methods 68:89-96. doi: 10.1016/j. ymeth.2014.02.033. PMID: 24613678.

Sarthy JF, Meers MP, Janssens DH, Henikoff JG, Feldman H, Paddison PJ, Lockwood CM, Vitanza NA, Olson JM, Ahmad K, Henikoff S (2020). Histone deposition pathways determine the chromatin landscapes of $\mathrm{H} 3.1$ and $\mathrm{H} 3.3 \mathrm{~K} 27 \mathrm{M}$ oncohistones. Elife 9. pii: e61090. doi: 10.7554/eLife.61090. PMID: 32902381.
Schwartzentruber J, Korshunov A, Liu XY, Jones DT, Pfaff E, Jacob K, Sturm D, Fontebasso AM, Quang DA, Tönjes M, Hovestadt V, Albrecht S, Kool M, Nantel A, Konermann C, Lindroth A, Jäger N, Rausch T, Ryzhova M, Korbel JO, Hielscher T, Hauser P, et al (2012). Driver mutations in histone H3.3 and chromatin remodelling genes in paediatric glioblastoma. Nature 482:226-31. doi: 10.1038/nature10833. PMID: 22286061.

Shah RN, Grzybowski AT, Cornett EM, Johnstone AL, Dickson BM, Boone BA, Cheek MA, Cowles MW, Maryanski D, Meiners MJ, Tiedemann RL, Vaughan RM, Arora N, Sun ZW, Rothbart SB, Keogh MC, Ruthenburg AJ (2018). Examining the Roles of H3K4 Methylation States with Systematically Characterized Antibodies. Mol Cell 72:162-177.e7. doi: 10.1016/j. molcel.2018.08.015. PMID: 30244833.

Stafford JM, Lee CH, Voigt P, Descostes N, Saldaña-Meyer R, Yu JR, Leroy G, Oksuz O, Chapman JR, Suarez F, Modrek AS, Bayin NS, Placantonakis DG, Karajannis MA, Snuderl M, Ueberheide B, Reinberg D (2018). Multiple modes of PRC2 inhibition elicit global chromatin alterations in H3K27M pediatric glioma. Sci Adv. 4:eaau5935. doi: 10.1126/sciadv. aau5935. PMID: 30402543.

Takahashi K, Yamanaka S (2006). Induction of pluripotent stem cells from mouse embryonic and adult fibroblast cultures by defined factors. Cell 126:663-76. PMID: 16904174.

Wen H, Andrejka L, Ashton J, Karess R, Lipsick JS (2008). Epigenetic regulation of gene expression by Drosophila Myb and E2F2-RBF via the Myb-MuvB/dREAM complex. Genes Dev. 22:601-14. doi: 10.1101/gad.1626308. PMID: 18316477.

Williams JA, Bell JB, Carroll SB (1991). Control of Drosophila wing and haltere development by the nuclear vestigial gene product. Genes Dev. 5:2481-95. PMID: 1752439.

Wu G, Diaz AK, Paugh BS, Rankin SL, Ju B, Li Y, Zhu $X, Q u$ C, Chen X, Zhang J, Easton J, Edmonson M, Ma X, Lu C, Nagahawatte P, Hedlund E, Rusch M, Pounds S, Lin T, Onar-Thomas A, Huether R, Kriwac$\mathrm{ki}$ R, et al (2014). The genomic landscape of diffuse intrinsic pontine glioma and pediatric non-brainstem high-grade glioma. Nat Genet. 46:444-450. doi: 10.1038/ng.2938. PMID: 24705251.

Wu G, Broniscer A, McEachron TA, Lu C, Paugh BS, Becksfort J, Qu C, Ding L, Huether R, Parker M, Zhang J, Gajjar A, Dyer MA, Mullighan CG, Gilbertson 
RJ, Mardis ER, Wilson RK, Downing JR, Ellison DW, Zhang J, Baker SJ et al (2012). Somatic histone H3 alterations in pediatric diffuse intrinsic pontine gliomas and non-brainstem glioblastomas. Nat Genet. 44:2513. doi: 10.1038/ng.1102. PMID: 22286216.

Yamaguchi N (2020). Multiple Roles of Vestigial-Like Family Members in Tumor Development. Front Oncol. 10:1266. doi: 10.3389/fonc.2020.01266. PMID: 32793503.

Zhu J, Ordway AJ, Weber L, Buddika K, Kumar JP. Polycomb group (PcG) proteins and Pax6 cooperate to inhibit in vivo reprogramming of the developing Drosophila eye. Development 145. pii: dev160754. doi: 10.1242/dev.160754. PMID: 29530880.

\section{Supplementary Materials:}

\section{Supplementary Information}

Lists of chromatin profiling sites.

\section{Supplementary Note}

Data processing for Figures 5, 6, and Supplementary Figure 1.

New data: All sequencing data is deposited in GEO under the super-entry (in progress).

Published data: EPDnew, FB 20202_3, Naval-Sanchez et al 2013 (GSE59059, wing imaginal disc and GSE59059,eye imaginal disc), Loubiere et al 2016 (GSE74080, Pc profiling in eye imaginal discs).

Software packages used: deepTools v. 3.3.2 in usegalaxy.edu

Extracting promoter signals: mean signal coverage +500 bp around EPDnew annotated gene TSSs was extracted using 'multibigwigSummary' in deepTools. Values for each dataset are provided in Supplementary Information.

Extracting H3K27me3 domain signals: mean coverage across annotated $\mathrm{H} 3 \mathrm{~K} 27$ me 3 domains was extracted using 'multibigwigSummary' in deepTools. Values for each dataset are provided in Supplementary Information.

Defining differentially-expressed genes: RNA-seq count tables for wildtype eye and wing imaginal discs [Naval-Sanchez et al, 2013] were displayed in degust v. 4.1 .1 (degust.erc.monash.edu), and differentially-expressed genes were selected with a $>1.5$ fold change cutoff. This list is provided in Supplementary Information.

Heatmapping: In all cases heatmaps display $-1 \mathrm{~kb}$ to
+2 kb around annotated TSSs of genes with $10 \mathrm{bp}$ signal binning, ordered by mean signal and plotted using deepTools. The display range was adjusted to the maximum and minimum signals for each heatmap, and the number of regions is reported in the figures.

For Figure 5A: UCSC Genome Browser tracks for H3K27me3 (red) datasets 1534 (w eye discs), 1732 (w wing discs), 1805 (>Vg eye discs), 1800 (>H3.3K27M eye discs), 1806 (>H3.3K27M > Vg eye discs) were plotted with autoscaling.

For Figure 5B: UCSC Genome Browser tracks for H3K27me3 (red) datasets 1534 (w eye discs) and 1732 (w wing discs) were plotted with autoscaling.

For Figure 5C: Mean H3K27me3 signal across annotated H3K27me3 domains and background regions was plotted in MS Excel.

For Figure 5D: Mean H3K27me3 signal across annotated H3K27me3 domains and the average of background regions was rank-ordered for each sample and heatmapped using three-color conditional formatting in MS Excel with Green-Yellow-Red for low-tohigh values. Selected values are shown in the figure. The full domain list is provided in Supplementary Information.

For Figure 5E: We used 2000 called Polycomb-bound sites in eye imaginal discs [Loubiere et al, 2016] and selected the top 700 sites that fall within H3K27me3marked domains. This list is provided in Supplementary Information. We extracted and displayed mean H3K27me3 signal $+20 \mathrm{~kb}$ around these sites using the 'computematrix' and 'plotHeatmap' functions of deepTools with 10 bp binning. Plots were individually scaled to the maximum mean signal in each dataset. The following datasets were used: 1805 (>Vg eye discs); 1800 (>H3.3K27M eye discs); and 1806 (>H3.3K27M $>\mathrm{Vg}$ eye discs).

For Figure 6A: Bedgraph files for $\mathrm{H} 3 \mathrm{~K} 4 \mathrm{me} 2$ profiling were used for heatmapping around EPDnew promoters by the 'computematrix' with $10 \mathrm{bp}$ binning and 'plotHeatmap' functions in deepTools. This promoter list is provided in Supplementary Information. Promoters were ordered by decreasing signal and displayed in the 'YIGnBu' color map. Datasets 1813 (w eye discs) and 1808 (w wing discs) were used.

For Figure 6B, C: UCSC Genome Browser tracks for H3K27me3 (red) and H3K4me2 (blue) datasets 1534 (w eye discs, H3K27me3), 1813 (w eye discs, H3K4me2), 1732 (w wing discs, H3K27me3), and 1808 (w wing discs, H3K4me2) were plotted with 
autoscaling.

For Figure 6D: Mean H3K4me2 signal across all EPDnew annotated promoters was rank-ordered for each sample and heatmapped using three-color conditional formatting in MS Excel with Red-Yellow-Green for low-to-high values. Selected values are shown in the figure. The full list is provided in Supplementary Information. Datasets 1813 (w eye discs); and 1808 (w wing discs) were used.

For Supplementary Figure 1A: Spearman correlations for all H3K27me3 profiling. Bedgraph files were binned into $5 \mathrm{~kb}$ windows, and correlations between the datasets were generated and displayed by the 'plotcorrelation' function in deepTools.

For Supplementary Figure 1B: Spearman correlations for all H3K4me2 profiling. Bedgraph files were binned into 500 bp windows, and correlations between the datasets were generated and displayed by the 'plotcorrelation' function in deepTools.

For Supplementary Figure 1C: Spearman correlations for all K27M profiling. Bedgraph files were binned into $5 \mathrm{~kb}$ windows, and correlations between the datasets were generated and displayed by the 'plotcorrelation' function in deepTools.

For Supplementary Figure 1D: Bedgraph files for $\mathrm{K} 27 \mathrm{M}$ profiling were used for heatmapping around EPDnew promoters by the 'computematrix' with 10 bp binning and 'plotHeatmap' functions in deepTools. This promoter list is provided in Supplementary Information, Sheet 2. Promoters were ordered by decreasing signal and displayed in the 'greys' color map. 1802 (>H3.3K27M eye discs); and 1769 (>H3.3K27M > Vg eye discs) datasets were used.

For Supplementary Figure 1E: H3K4me2 signal was binned into $500 \mathrm{bp}$ and displayed using the 'multibigwigSummary' and 'plotPCA' functions in deepTools.

For Supplementary Figure 1F: H3K27me3 signal was binned into $5 \mathrm{~kb}$ windows and displayed using the 'multibigwigSummary' and 'plotPCA' functions in deepTools.
Supplementary Figure 1. (A) Spearman correlations between H3K27me3 profiling samples. (B) Spearman correlations between H3K4me2 profiling samples. (C) Spearman correlations between K27M profiling samples. (D) Heatmap of K27M signal centered on promoters in $>H 3.3 \mathrm{~K} 27 \mathrm{M}$ and $>H 3.3 \mathrm{~K} 27 \mathrm{M}>\mathrm{Vg}$ eye discs. (E) PCA plot of H3K4me2 signal in all samples. (F) PCA plot of H3K27me3 signal in all samples. 
bioRxiv preprint doi: https://doi.org/10.1101/2020.11.10.375881; this version posted November 11,2020 . The copyright holder for this preprint (which was not certified by peer review) is the author/funder, who has granted bioRxiv a license to display the preprint in perpetuity. It is made available under aCC-BY-NC-ND 4.0 International license.

\section{Supplementary Figure 1}

A

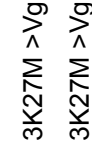

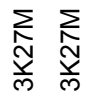

ले ले क्ष

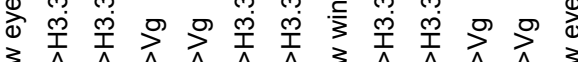

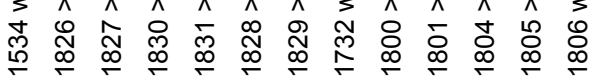

\begin{tabular}{|l|l|l|l|l|l|l|l|l|l|l|l|l|l|l}
\hline 0.80 & 0.84 & 0.83 & 0.84 & 0.83 & 0.79 & 0.80 & 0.83 & 0.86 & 0.86 & 0.84 & 0.88 & 1.00 & $1806 \mathrm{w}$ eye \\
\hline 0.81 & 0.85 & 0.86 & 0.87 & 0.86 & 0.80 & 0.81 & 0.82 & 0.84 & 0.84 & 0.85 & 1.00 & 0.88 & $1805>\mathrm{Vg}$ \\
\hline 0.79 & 0.82 & 0.80 & 0.82 & 0.81 & 0.78 & 0.79 & 0.81 & 0.82 & 0.83 & 1.00 & 0.85 & 0.84 & $1804>\mathrm{Vg}$ \\
\hline 0.81 & 0.82 & 0.81 & 0.82 & 0.81 & 0.79 & 0.79 & 0.83 & 0.86 & 1.00 & 0.83 & 0.84 & 0.86 & $1801>\mathrm{H} 3.3 \mathrm{~K} 27 \mathrm{M}$ \\
\hline 0.80 & 0.82 & 0.80 & 0.82 & 0.80 & 0.78 & 0.78 & 0.83 & 1.00 & 0.86 & 0.82 & 0.84 & 0.86 & $1800>\mathrm{H} 3.3 \mathrm{~K} 27 \mathrm{M}$
\end{tabular}

\begin{tabular}{l|l|l|l|l|l|l|l|l|l|l|l|l|l|l|l|l}
\hline 0.79 & 0.80 & 0.77 & 0.80 & 0.79 & 0.76 & 0.76 & 1.00 & 0.83 & 0.83 & 0.81 & 0.82 & 0.83 & 1732 & w wing
\end{tabular}

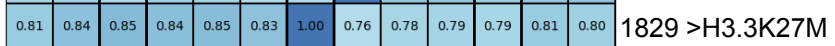

\begin{tabular}{|l|l|l|l|l|l|l|l|l|l|l|l|l|l|l|l}
\hline 0.80 & 0.83 & 0.84 & 0.84 & 0.84 & 1.00 & 0.83 & 0.76 & 0.78 & 0.79 & 0.78 & 0.80 & 0.79 & $1828>\mathrm{H} 3.3 \mathrm{~K} 27 \mathrm{M}$
\end{tabular}

\begin{tabular}{|l|l|l|l|l|l|l|l|l|l|l|l|l|l|l|}
\hline 0.84 & 0.86 & 0.89 & 0.90 & 1.00 & 0.84 & 0.85 & 0.79 & 0.80 & 0.81 & 0.81 & 0.86 & 0.83 & $1831>V g$
\end{tabular}

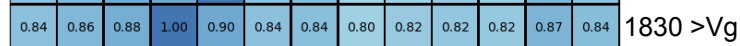

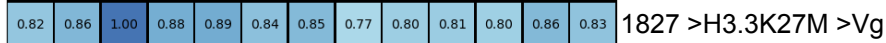

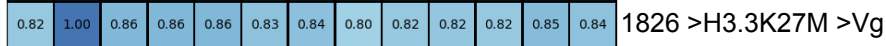

\begin{tabular}{lll|l|l|l|l|l|l|l|l|l|l|l|l|l}
\hline 00 & 0.82 & 0.82 & 0.84 & 0.84 & 0.80 & 0.81 & 0.79 & 0.80 & 0.81 & 0.79 & 0.81 & 0.80 & 1534 w eye
\end{tabular}

C

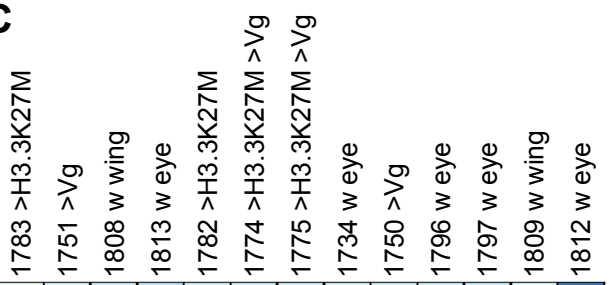

\begin{tabular}{|l|l|l|l|l|l|l|l|l|l|l|l|l|l|}
\hline 0.65 & 0.68 & 0.71 & 0.74 & 0.70 & 0.70 & 0.70 & 0.68 & 0.70 & 0.71 & 0.72 & 0.67 & 1.00 & 1812 w eye \\
\hline 0.68 & 0.71 & 0.75 & 0.77 & 0.73 & 0.73 & 0.73 & 0.74 & 0.73 & 0.74 & 0.75 & 1.00 & 0.67 & 1809 w wing \\
\hline 0.78 & 0.84 & 0.82 & 0.87 & 0.87 & 0.87 & 0.86 & 0.85 & 0.86 & 0.92 & 1.00 & 0.75 & 0.72 & 1797 w eye \\
\hline
\end{tabular}

\begin{tabular}{|l|l|l|l|l|l|l|l|l|l|l|l|l|l}
\hline 0.77 & 0.83 & 0.81 & 0.86 & 0.85 & 0.85 & 0.84 & 0.85 & 0.86 & 1.00 & 0.92 & 0.74 & 0.71 & $1796 \mathrm{w}$ eye
\end{tabular}

\begin{tabular}{|l|l|l|l|l|l|l|l|l|l|l|l|l|l|l|}
\hline 0.77 & 0.82 & 0.80 & 0.83 & 0.84 & 0.85 & 0.85 & 0.84 & 1.00 & 0.86 & 0.86 & 0.73 & 0.70 & $1750>\mathrm{Vg}$
\end{tabular}

\begin{tabular}{|l|l|l|l|l|l|l|l|l|l|l|l|l|l|}
\hline 0.78 & 0.81 & 0.82 & 0.82 & 0.84 & 0.83 & 0.83 & 1.0 & 0.84 & 0.85 & 0.85 & 0.74 & 0.68 & 1734 w eye
\end{tabular}

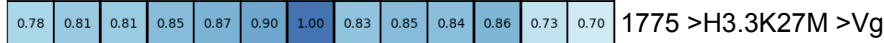

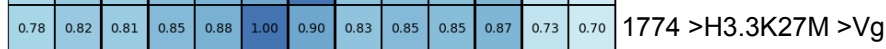

\begin{tabular}{|l|l|l|l|l|l|l|l|l|l|l|l|l|l|l|l|l}
\hline 0.79 & 0.80 & 0.80 & 0.85 & 1.00 & 0.88 & 0.87 & 0.84 & 0.84 & 0.85 & 0.87 & 0.73 & 0.70 & $1782>\mathrm{H} 3.3 \mathrm{~K} 27 \mathrm{M}$
\end{tabular}

\begin{tabular}{l|l|l|l|l|l|l|l|l|l|l|l|l|l|}
\hline 0.77 & 0.80 & 0.84 & 1.00 & 0.85 & 0.85 & 0.85 & 0.82 & 0.83 & 0.86 & 0.87 & 0.77 & 0.74 & $1813 \mathrm{w}$ eye
\end{tabular}

\begin{tabular}{|l|l|l|l|l|l|l|l|l|l|l|l|l|l|}
\hline 0.74 & 0.78 & 1.00 & 0.84 & 0.80 & 0.81 & 0.81 & 0.82 & 0.80 & 0.81 & 0.82 & 0.75 & 0.71 & $1808 w$ wing
\end{tabular}

\begin{tabular}{|l|l|l|l|l|l|l|l|l|l|l|l|l|l|l|l|l}
\hline 0.74 & 1.00 & 0.78 & 0.80 & 0.80 & 0.82 & 0.81 & 0.81 & 0.82 & 0.83 & 0.84 & 0.71 & 0.68 & $1751>V g$
\end{tabular}

\begin{tabular}{l|l|l|l|l|l|l|l|l|l|l|l|l|l|l|l|l}
1.00 & 0.74 & 0.74 & 0.77 & 0.79 & 0.78 & 0.78 & 0.78 & 0.77 & 0.77 & 0.78 & 0.68 & 0.65 & $1783>\mathrm{H} 3.3 \mathrm{~K} 27 \mathrm{M}$
\end{tabular}
B

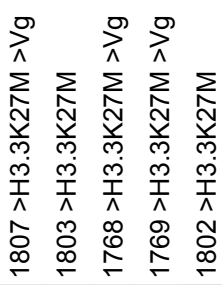

H3.3K27M

$5 \mathrm{~kb}$ bins

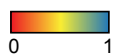

D $\quad \mathrm{K} 27 \mathrm{M}$

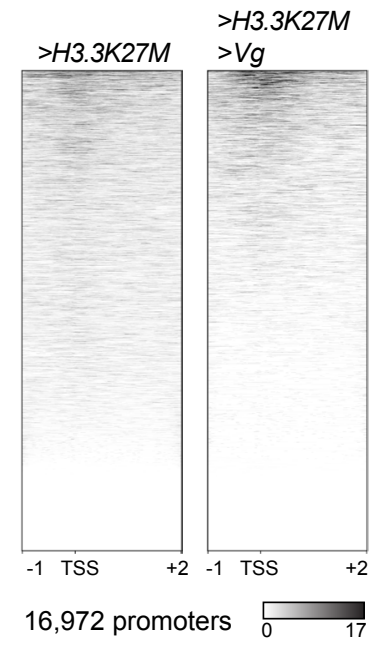

E

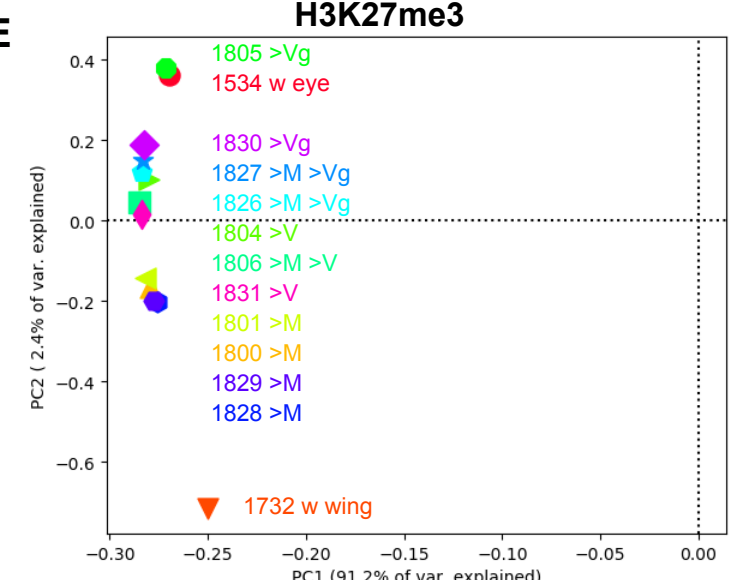

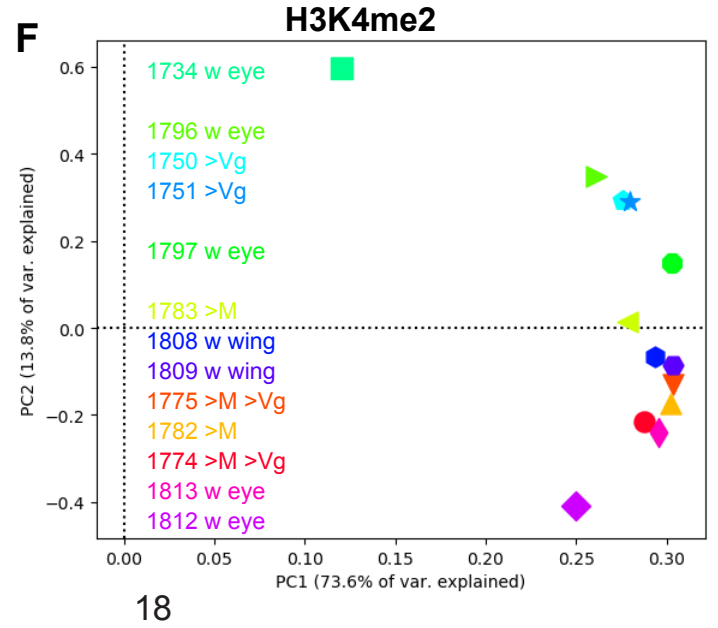


bioRxiv preprint doi: https://doi.org/10.1101/2020.11.10.375881; this version posted November 11, 2020. The copyright holder for this preprint

(which was not certified by peer review) is the author/funder, who has granted bioRxiv a license to display the preprint in perpetuity. It is made available under aCC-BY-NC-ND 4.0 International license.

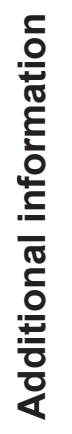

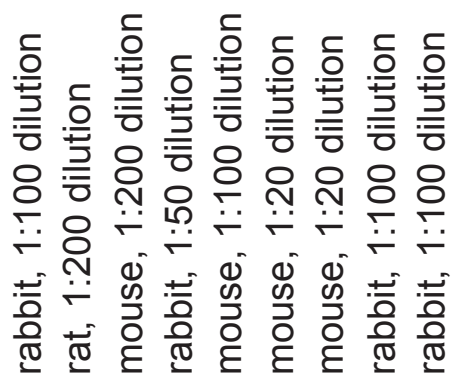

$\frac{\pi}{\frac{\pi}{1}}$

๓

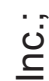

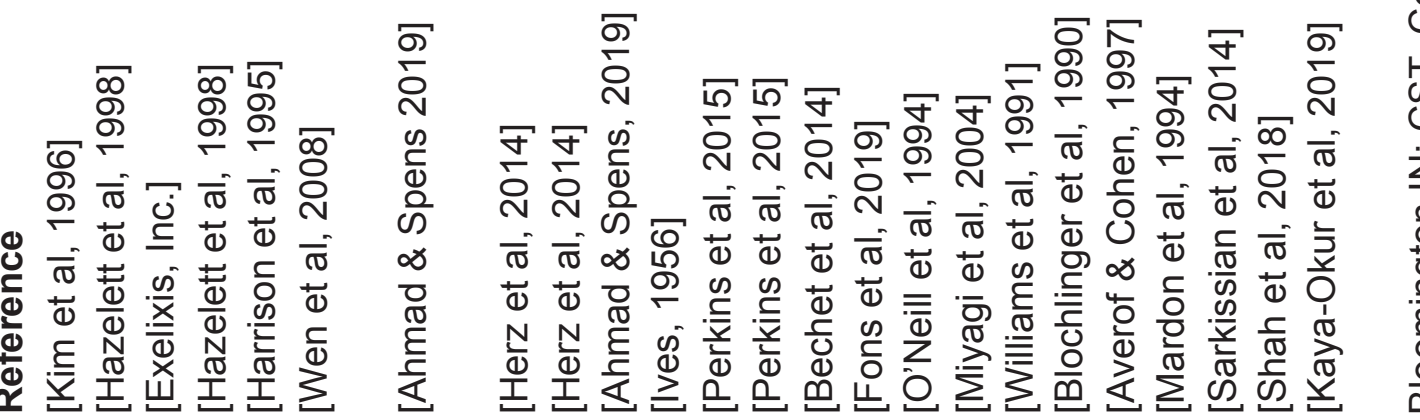

$\frac{0}{\frac{0}{0}}$

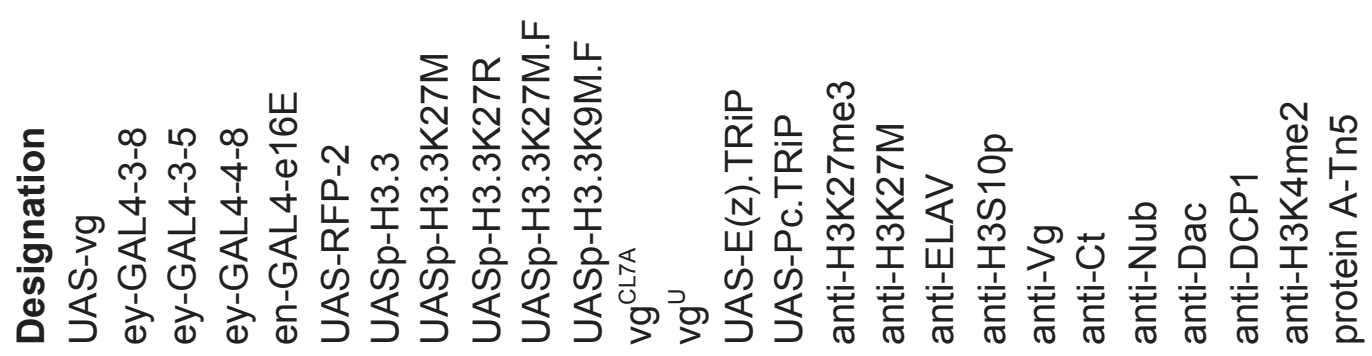

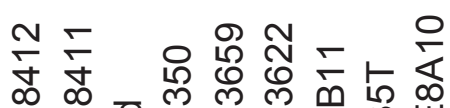

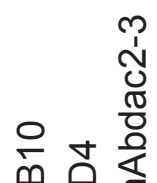

กิ

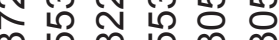

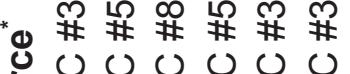

$>>>$

\# $m$

ต

茴

W

๙

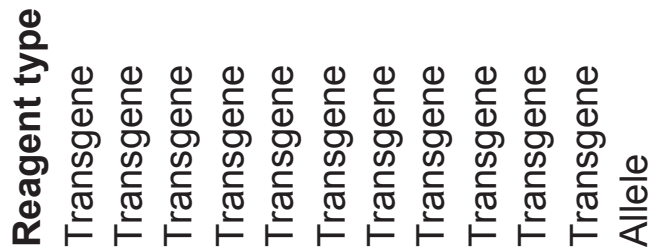

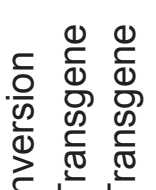

